\title{
LA FIGURA DE PEDRO EN LOS ESCRITOS DE PABLO*
}

Dedicado a Rafael Aguirre, con aprecio y admiración

Es casi un clásico, particularmente a partir del enfrentamiento entre Simón y Saulo en Antioquía, interpretar o suponer que entre ambos -y por tanto, entre sus teologías- hay una importante distancia, cuando no un abismo. También es clásico afirmar que escritores como M. Lutero o F. C. Baur hablan de una clara oposición teológica entre Pedro y Pablo... ${ }^{1}$

El presente trabajo se propone mostrar cómo "lee" Pablo el ministerio petrino. Para ello nos referiremos, en un primer momento, a lo histórico del "(des)encuentro" de ambos, especialmente porque -como veremos- no es fácil discernir con cierta seguridad los elementos necesarios para elaborar una cronología segura. En un segundo momento nos detendremos en aquello que podemos reconocer de la manera en que el "apóstol de los gentiles" se relaciona con una de las "columnas" de la Iglesia de Jerusalén y a su vez el "apóstol de la circuncisión”; para eso intentaremos analizar cómo ve Pablo el ministerio de Kefas.

El presente trabajo tiene su origen en una conferencia organizada por la Escuela Bíblica "Nuestra Señora de Sión" -con motivo de la elección de Benito XVI como Obispo de Roma- sobre "Pedro en el Nuevo Testamento".

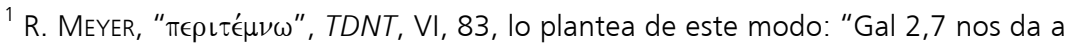
entender que en Jerusalén, en rigor, sólo se toma conocimiento de la libertad respecto del loudaïsmós y que, en realidad, ambos frentes se mantuvieron plenamente en sus lealtades respectivas. De allí en adelante quedaron Pablo [...] y Pedro [...] sin que la antítesis teológica fuese clarificada". 


\section{El aspecto histórico}

Como es evidente, para poder acceder a diferentes elementos históricos de la vida de Pablo, y en este caso de su relación con Pedro, es necesario precisar las fuentes. Sólo los Hechos de los Apóstoles y las cartas paulinas nos permiten reunir algunos elementos. La carta llamada "Primera de Pedro" parece establecer cierta conexión entre Pedro y Pablo, pero no aporta elementos históricos útiles (ni fiables). Una vez precisados los elementos históricos, podremos pasar al aspecto teológico: ¿qué dice Pablo sobre (el ministerio de) Pedro?

Para comenzar, detengámonos en el libro de Hechos.

Como es sabido, Lucas $^{2}$ da muchísima importancia a Jerusalén en su escrito. La segunda obra lucana es ciertamente misionera, y cada misión concluye en la ciudad santa; ${ }^{3}$ sólo en Jerusalén se encuentran Pedro y Pablo en Hechos. En el caso de Pablo (obviamente nos referimos al "Pablo cristiano", no a su etapa anterior), son muchos los viajes que realiza: éstos parecen ser seis. El primero en 9,26, después de escapar de Damasco; pero allí no le creen "que es discípulo" y es Bernabé quien lo presenta ante "los apóstoles". De allí es derivado a Tarso, donde Bernabé lo busca, aparentemente para hacerse cargo junto con él de la comunidad de Antioquía. Precisamente esta comunidad los envía en un segundo viaje a Jerusalén, con motivo del hambre $(11,30)$. En 12,24 Lucas recurre a la fórmula que va estructurando su obra: "la Palabra de Dios crecía y se multiplicaba" y a continuación dice, literalmente, "Bernabé y Saulo volvieron habiendo cumplido su ministerio a (eis) Jerusalén" (12,25). En 15,2-4 nuevamente Saulo y Bernabé son "enviados" ${ }^{4}$ por la comunidad de Antioquía a Jerusalén para tratar con "los apóstoles y presbíteros" la cuestión de la circuncisión. A continuación de esta asamblea, y luego de un conflicto con Bernabé, Pablo -ahora acompañado por Silas- comienza

${ }^{2}$ No pretendemos, con esto, fijar posición sobre el autor de Lc-Hch. Sí pensamos que se trata de un mismo autor para ambos escritos. Convencionalmente lo llamamos "Lucas"; cf. E. DE LA SERNA, Hechos de los Apóstoles. El relato. El ambiente. Las enseñanzas, Claretiana - Buenos Aires - 2004, 68-74.

3 Para referirse a la "ciudad santa", Lucas utiliza dos términos: Hierosólyma y Ierousalém. El primero parece más "secular", mientras el segundo parece más "sagrado".

${ }^{4}$ Los verbos utilizados por Lucas para aludir al "envío" de Pablo son variados: pémpō, propémpō, apostéllō. Es sabido que evita llamar "apóstol" a Pablo (con excepción de 14,14), aunque es "enviado" por la comunidad antioquena (aposteilantas en 15,33; ver 11,30) y por el mismo Jesús que lo envía (apostéllō) a los gentiles $(26,17)$. 
su segundo viaje misionero; al finalizar, y antes de dirigirse a Antioquía, vuelve a la ciudad $(18,22$; el verbo "subir" es indicio de que se refiere a Jerusalén). El tercer viaje misionero también concluye en Jerusalén donde, en este caso, es capturado y apresado para ya no volver a moverse con libertad $(21,17)$. Como también es sabido, para Hechos esta prisión culminará en Roma, desde donde Pablo ya no volverá a Jerusalén pues ha llegado a su culmen el anuncio (el crecimiento de la Palabra) hasta los "confines de la tierra" $(1,8)$.

Si miramos, en cambio, los escritos paulinos, veremos que Pablo ha ido a la ciudad aparentemente sólo en dos ocasiones: la primera al escapar de Damasco (2 Cor 11,33; Gal 1,18) y la segunda con motivo de la asamblea (Gal 2,1). También sabemos que planea dirigirse a Jerusalén para llevar el fruto de la colecta (Rom 15,25; cf. 2 Cor 1,16), aunque finalizan sus escritos sin que sepamos cómo concluye este cometido.

Teniendo en cuenta ambas fuentes, aparentemente podemos afirmar que la visita con ocasión del hambre a la que alude Hch 11,30 parece, en realidad, un duplicado de aquella visita para la asamblea: Pablo afirma (Gal 2,10) que la única indicación que le dieron fue ocuparse de los pobres; con lo cual, 'ayuda a la comunidad' y 'discusión sobre el Evangelio' parecen ser parte integrante de un mismo viaje. En cuanto al otro aparente viaje (Hch 12,25), parece que el texto debe leerse: “cumplido su ministerio en ${ }^{5}$ Jerusalén, se volvieron (a Antioquía)" y no "cumplido su ministerio, volvieron a Jerusalén". Notemos, entonces, que -como es frecuente en Lucas- algunos hechos parecen duplicados mientras que otros que ocurren en diferentes circunstancias parecen unificados. Lucas tiende, en algunos casos, a simplificar: la asamblea de Jerusalén parece aludir a diferentes acontecimientos (el discurso de Santiago y la carta apostólica no parecen ni literaria ni cronológicamente coherentes en este lugar) y los viajes de Pablo, estructurados en tres "círculos" misioneros, parecen ser bastante más complejos en realidad. En efecto, la narración de la visita a Corinto -por ejemplo- parece aludir a dos viajes, más que a uno (por ejemplo, el jefe de la sinagoga en 18,8 es

${ }^{5}$ El término eis tiene una importante variedad de acepciones, entre ellas se utiliza "cuando se esperaría en" (BDAG, que entre otras citas en las que se utiliza en este sentido, propone Hch 2,5.25; 7,4; 8,40; 21,13; cf. 2,39). Es interesante que, dentro de todas las acepciones que menciona (10 en total con variantes en cada caso), el BDAG no alude a Hch 12,25 salvo en una posibilidad -que aparentemente no acepta- citando a J. Dupont, entendida como una "acción hacia alguien en sentido hostil o amigable". 
Crispo y en 18,17 es Sóstenes). Sin embargo, Lucas también tiende a duplicar $-\mathrm{o}$ triplicar- acontecimientos que quiere reforzar: narra dos veces la visión de Pedro sobre Cornelio, y alude a ella una tercera vez; narra tres veces la "conversión" de Saulo ("redundancia funcional", según R. D. Witherup ${ }^{6}$ ). Por esto podemos sospechar válidamente que la frecuencia de viajes de Pablo a Jerusalén sea históricamente menor a la narrada por Hechos.

Es interesante notar - por otra parte- que Hechos presenta a Pablo en estrecha relación con Bernabé $\mathrm{y}$, asimismo, con la comunidad de Antioquía. Ambos personajes aparecen como "enviados" de esta comunidad y ya definitivamente desarraigados de la comunidad de Jerusalén.

Precisamente, pensamos que la intención de evitar atribuir a Pablo el término "apóstol" y el recurso a anacronismos como la mención de "presbíteros", ${ }^{7}$ puede darnos un indicio de la intención de Lucas al componer Hechos de los apóstoles: su objetivo es presentar el crecimiento de la Palabra de Dios; de allí que el protagonista principal sea el Espíritu Santo. ${ }^{8}$ Este espíritu es garante de esta progresión: de Jesús a los apóstoles, de éstos a sus enviados o elegidos (los Siete y luego Pablo) y de éstos a los presbíteros. No es por azar que el único discurso dirigido a cristianos en Hechos, sea de Pablo a los "presbíteros" y aluda a "después de mi partida" $(20,29) .{ }^{9}$

A la sospecha de una multiplicación de visitas a Jerusalén, debemos ahora añadir un nuevo elemento a la obra lucana. Es sabida su intención de presentar una "geografía teológica", hacia Jerusalén en Lc y desde Jerusalén a los "confines de la tierra" en Hch. Sin embargo, esa intención geográfica conduce a Lucas a imprecisiones, a modificación de

${ }^{6}$ R. D. Witherup, "Functional Redundancy in the Acts of the Apostles: A Case Study", JSNT 48 (1992) 67-86; íD., "Cornelius Over and Over and Over Again: 'Functional Redundancy' in the Acts of the Apostles", JSNT 49 (1993) 45-66.

${ }^{7}$ Notar que el término "presbýteros" jamás se encuentra en las cartas auténticas de Pablo; sólo en Flm 9 usa un término de la misma raíz: presbýtēs, en el que todo parece indicar que alude a su edad (difícilmente a que Pablo se vea como "embajador"). Ciertamente es posible que el término presbýteroi sea más palestinense, mientras Pablo se mueve en un ambiente helenista; pero de todos modos parece tardío.

${ }^{8}$ Es probable que por "espíritu" no deba entenderse "el" Espíritu Santo sino "un" espíritu santo, como lo señala C. TIBBS, "The Spirit (World) and the (Holy) Spirits among the Earliest Christians: 1 Corinthians 12 and 14 as a Test Case", CBQ 70 (2008) 313330.

${ }^{9}$ Se ha notado con justicia que el discurso de Mileto tiene semejanzas con otros textos pastorales tardíos (1 Pe; 1 Tim). 
datos o a traslado de escenas de un momento cronológico a otro, a fin de darle coherencia. Un ejemplo es la "ida" de Pedro de Jerusalén (Hch 12,17), que narrativamente parece definitiva, aunque lo volvemos a encontrar más tarde allí para la asamblea. ${ }^{10}$ Otro ejemplo, más importante, es el paralelismo que presenta en la estructuración de los dos tomos de la obra. No sólo hay una notable semejanza en el comienzo de uno y otro tomo, sino que también lo hay en la conclusión. Veamos:

\begin{tabular}{|c|c|c|c|}
\hline Lc & Jesús & Pablo & Hch \\
\hline 9,51 & $\begin{array}{l}\text { "decidió resueltamente } \\
\text { dirigirse (poreúomai) a } \\
\text { Jerusalén" }\end{array}$ & $\begin{array}{l}\text { "Después de estos sucesos, } \\
\text { Pablo tomó la decisión de } \\
\text { dirigirse (poreúomai), pasando } \\
\text { por Macedonia y Acaya, a } \\
\text { Jerusalén. Y decía: 'Después } \\
\text { de estar allí, conviene }(d e \hat{l}) \\
\text { que vaya también a Roma'" }\end{array}$ & 19,21 \\
\hline 13,33 & $\begin{array}{l}\text { "Pero conviene }(d e \hat{\imath}) \text { que hoy } \\
\text { y mañana y el día que sigue, } \\
\text { avance, porque no es } \\
\text { aceptable que un profeta } \\
\text { perezca fuera de Jerusalén" }\end{array}$ & $\begin{array}{l}\text { "pues yo no sólo estoy } \\
\text { dispuesto a ser atado, sino } \\
\text { también a morir en Jerusalén } \\
\text { por el nombre del Señor } \\
\text { Jesús" }\end{array}$ & 21,13 \\
\hline $23,18.21$ & $\begin{array}{l}\text { "pero gritaron al unísono } \\
\text { diciendo: 'iquítalo (aîre) a } \\
\text { este...!!" }\end{array}$ & $\begin{array}{l}\text { "pero lo seguía la multitud del } \\
\text { pueblo gritando: '¡Quítalo! } \\
\text { (aîre) })^{\prime \prime \prime}\end{array}$ & $\begin{array}{l}21,36 \\
(22,22)\end{array}$ \\
\hline 22,66 & $\begin{array}{l}\text { "Cuando se hizo de día, se } \\
\text { reunió (synéjthē) el concejo de } \\
\text { los ancianos del pueblo, los } \\
\text { sumos sacerdotes y los } \\
\text { escribas, y lo llevaron ante su } \\
\text { asamblea (synédrion)" }\end{array}$ & $\begin{array}{l}\text { "Entonces Pablo, mirando } \\
\text { fijamente la asamblea } \\
\text { (synédrion), dijo..." }\end{array}$ & 23,1 \\
\hline $\begin{array}{l}20,20 ; \\
21,12\end{array}$ & $\begin{array}{l}\text { "(Buscaban) poderlo entregar } \\
\text { al poder y autoridad del } \\
\text { gobernador (hēgemón)" }\end{array}$ & $\begin{array}{l}\text { "después de cinco días bajó el } \\
\text { Sumo Sacerdote Ananías con } \\
\text { algunos ancianos y un tal } \\
\text { Tértulo, abogado, quienes } \\
\text { presentaron ante el } \\
\text { gobernador (hēgemón) sus } \\
\text { cargos contra Pablo" }\end{array}$ & $\begin{array}{l}23,24.26 ; \\
24,1\end{array}$ \\
\hline
\end{tabular}

${ }^{10}$ Esto lleva al Libro del Pueblo de Dios a cometer el error de afirmar que "[a] partir de este relato, Pedro ya no vuelve a ser mencionado en el libro de los Hechos" (nota a 12,17), cuando evidentemente en 15,7 lo volvemos a encontrar. 


\begin{tabular}{|l|l|l|l|}
23,15 & $\begin{array}{l}\text { "y he aquí que nada ha hecho } \\
\text { que merezca la muerte" } \\
(\text { áxios thanátou })\end{array}$ & $\begin{array}{l}\text { "...y encuentro que lo } \\
\text { acusaban sobre cuestiones de } \\
\text { su ley, pero nada por lo que } \\
\text { mereciera muerte (áxios } \\
\text { thanátou) o prisión" }\end{array}$ & 23,29 \\
\hline 23,7 & $\begin{array}{l}\text { "Y, al saber que era } \\
\text { jurisdicción de Herodes, lo } \\
\text { envió a Herodes [Antipas], } \\
\text { que estaba también él en } \\
\text { Jerusalén por aquellos días" }\end{array}$ & $\begin{array}{l}\text { "Pasados algunos días, el rey } \\
\text { [Herodes] Agripa y Berenice } \\
\text { llegaron a Cesarea y fueron a } \\
\text { visitar a Festo" }\end{array}$ & 25,13 \\
\hline 23,14-15 & $\begin{array}{l}\text { "...no he hallado nada en este } \\
\text { hombre según las acusaciones } \\
\text { contra él. Ni tampoco } \\
\text { Herodes, pues nos lo ha } \\
\text { reenviado" }\end{array}$ & $\begin{array}{l}\text { "este hombre no ha hecho } \\
\text { nada que merezca muerte o } \\
\text { prisión" }\end{array}$ & 26,31 \\
\hline
\end{tabular}

Este paralelismo tan marcado nos invita a sospechar y dudar cuánto de lo allí narrado debe retenerse por histórico; o al menos, cuánto debe considerarse desplazado geográfica o cronológicamente o adaptado en orden a establecer este paralelo teológico-literario. ¿Es fiable el encuentro de Jesús con Herodes? ¿Y el de Pablo con otro "Herodes"? ${ }^{11}$ La intención de Lucas de poner en paralelo la pasión y muerte del discípulo con la pasión y muerte del maestro -como también es evidente en el caso de Esteban- nos invita, por lo menos, a sospechar de su fiabilidad histórica cuando no tenemos otro elemento independiente para confirmarlo.

Esto nos pone de lleno en el tema histórico de Pedro y Pablo. Es evidente que Lucas pretende ponerlos en paralelo también a ellos. Tanto en los acontecimientos como en los discursos, hay "vidas paralelas" que debemos destacar: ${ }^{12}$

${ }^{11}$ No es este el lugar para preguntarnos sobre la veracidad histórica o no de la prisión paulina y su traslado -encarcelado o no- a Roma. La mayoría lo afirma; lo niega D. Álvarez CinelRa, "Pablo, ¿un ciudadano romano?", EstAg 33 (1998) 455-486 y lo retoma en "La muerte de Pedro y Pablo en Roma", EstAg 39 (2004) 445-478.

${ }^{12}$ Este cuadro lo hemos presentado previamente en DE LA SERNA, Hechos, 47. 


\begin{tabular}{|c|l|c|}
\hline Pedro & \multicolumn{1}{|c|}{ acontecimientos } & Pablo \\
\hline $5,19(12,1 \mathrm{ss})$ & liberado de la cárcel & 16,26 \\
\hline $8,9-24$ & enfrentamiento con un mago & $13,6-12$ \\
\hline $3,1-10$ & curación de un tullido de nacimiento & $14,8-10$ \\
\hline $9,36-42$ & resucita a un/a muerto/a & $20,7-12$ \\
\hline cap. 2 & \multicolumn{1}{|c|}{ discursos (sermón a judíos) } & cap. $\mathbf{1 3}$ \\
\hline v. 22 & "Israelitas..." & v. 16 \\
\hline v. 29 & "Hermanos..." & v. 26 \\
\hline v. 27 & cita de Sal 16,10 & v. 35 \\
\hline vv. $29-34$ & comparación con David & vv. $36-37$ \\
\hline vv. 24.32 & "Dios lo resucitó" - testigos & vv. $30-31$ \\
\hline v. 38 & perdón de los pecados & v. 38 \\
\hline
\end{tabular}

Precisamente, esto nos conduce a dudar también de la verosimilitud histórica de la presentación de Pedro y Pablo. Creemos necesario tener una "segunda opinión independiente" para poder afirmar o negar con mayor probabilidad la historicidad de acontecimientos que nos permitan conocer la relación existente entre ambos. No es improbable que Lucas pretenda que Pablo - cuestionado por ciertos grupos cuando se compone su obra- alcance reconocimiento, para lo cual lo presenta "a la altura nada menos que de Pedro" (quizás eso también pretende Pablo en Gal 2, ante los que niegan su apostolado); tal vez por eso omita el conflicto de Antioquía, pero -como es evidente- nos movemos en el terreno de las hipótesis. Pero también es posible que la valoración tradicional de Pedro haga que sea él narrativamente el primero en dar ciertos pasos que en realidad son característicos de Pablo, como por ejemplo ser el primero en bautizar paganos sin exigir la circuncisión, como ocurre en el caso de Cornelio.

Pasando a los escritos paulinos, y siempre preguntándonos por lo "histórico", hay una serie de elementos que podemos confrontar a fin de conocer la relación de Pablo y Pedro.

A) En primer lugar, desde una mirada quizá "cronológica", debemos reconocer la primera aparición del resucitado a Pedro. De la misma habla Lc 24: es evidente que aquí la narración del tercer evangelio es diferente de los otros dos sinópticos, y en algún aspecto se aproxima a Juan. Los cuatro evangelios coinciden en afirmar que se trata del "primer día de la semana". Lc (como Mc) alude a los aromas preparados para 
ungir el cadáver de Jesús. Mientras Mt y Mc muestran el lugar donde lo pusieron, Lc señala que "no encontraron el cuerpo" y se les presentan "dos hombres" (un ángel [Mt], un joven [Mc], dos ángeles [Jn]). Las mujeres "inclinaron sus rostros en tierra" y los hombres les preguntan “¿por qué buscan entre los muertos al viviente?”. La referencia a que irá delante de ellos a Galilea se transforma en "recuerden lo que les dijo estando en Galilea", ya que todo ocurrirá en Jerusalén y su entorno. Los apóstoles no les creen, pero Pedro corre al sepulcro (en el cuarto evangelio lo hace acompañado del discípulo amado; es bueno notar que los peregrinos de Emaús afirman que "algunos [plural] de los nuestros también fueron al sepulcro" v. 24) y sólo ve las vendas. A pesar de la importancia que da a la mujer en su evangelio, Lc no presenta -como sí lo hacen Mt y Jn- una aparición del resucitado a las mujeres y en cambio se aparece a dos peregrinos de Emaús. Cuando éstos lo reconocen al partir el pan, corren a Jerusalén donde encuentran a los Once reunidos, que les dicen: "realmente se ha levantado (ègérthē) el Señor y se ha aparecido (ơfthē) a Simón" (v. 34). Es interesante también notar que en Mc no encontramos apariciones del resucitado; en Mt, la primera es a las mujeres; en Jn, es a María Magdalena (aunque ella también afirma: "no sabemos [plural] dónde lo han puesto...", 20,2); y en Lc, aunque narrativamente se aparece primero a los peregrinos de Emaús, la primera aparición es a Simón. Es esta tradición de la primera aparición (ófthē) a Simón-Kefas del resucitado (egégerthai) la que conoce Pablo (cf. 1 Cor 15), quien -además- no menciona mujeres en la lista de testigos de 1 Cor 15,5-8. Sin embargo, debemos reconocer en este texto una manifestación de la tradición pre-paulina, más que del Apóstol. Ya J. Jeremias, entre otros, señaló hace tiempo siete elementos o palabras que no son propios de Pablo, e incluso propuso un original semítico (que abarca $3 b-5) .{ }^{13}$ Señala también el estrecho paralelo con el texto de Lc.

Lo que podemos afirmar, entonces, es que Pablo manifiesta conocer la tradición -también conocida por Lucas- de que Pedro fue el

${ }^{13}$ Así J. Jeremias, La última cena. Palabras de Jesús, Madrid - 1980, 106-109. Je-

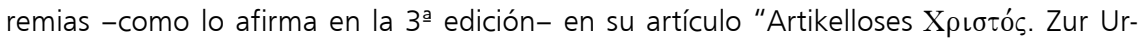
sprache von 1 Cor 15,3b-5", ZNW 57 (1966) 211-215, responde a las objeciones de Conzelmann. En 1969, a raíz de un artículo de E. Güttgemanns (1968), insiste en el

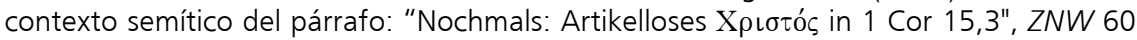
(1969) 214-219. De todos modos, es cierto que no todos los argumentos de Jeremias tienen el mismo peso: por ejemplo, que el texto aluda a Kefas y no a Simón o Pedro no es convincente ya que Pablo siempre lo llama Kefas, y la excepción de Gal 2,7-8 es más un problema que un signo de lo contrario, como veremos. 
primero en recibir una manifestación del resucitado y él se ve a sí mismo como un eslabón más de esta cadena, el último (ésjaton). Pablo se sabe apóstol y lo repite con convicción, puesto que él ha "visto al Señor" (heóraka, 1 Cor 9,1) y eso lo constituye "apóstol", 14 aunque es el más insignificante (elájistos) de los apóstoles por haber perseguido "a la Iglesia de Dios". Pablo afirma claramente que no es digno, no está "capacitado" (hikanós) pero que Dios "lo capacitó". 15

B) El segundo texto que nos interesa para conocer la relación entre Pablo y Pedro es el encuentro en Jerusalén, por la asamblea y luego el posterior encuentro en Antioquía.

Sobre la asamblea de Jerusalén hay diferentes opiniones entre los autores a la hora de datarla históricamente, o -quizá mejor dicho- de ubicarla en el contexto de los viajes paulinos. Hechos la ubica antes de las grandes misiones paulinas, y sólo después de un pequeño primer viaje misionero; pero esta misión comienza claramente con un discurso a judíos. Sólo cuando es rechazado se dirigen a paganos $(13,44-45)$; lo mismo ocurre en Iconio $(14,2)$. La intención clara es mostrar que "es necesario" (anagkaîos) que primero se predique a judíos y sólo cuando éstos lo rechazan se empieza a anunciar a los gentiles. Pero Pablo procede así también después de la asamblea de Jerusalén $(17,2.10 ; 18,4$; $19,8)$, lo que nos hace dudar si se trata de algo propio de la misión paulina, o en cambio, como parece, si no es algo propio de la teología de Lucas. La estrategia de predicación histórica de Pablo no parece fácil de precisar siguiendo la letra de Hechos.

Lo que también resulta difícil de precisar, con los datos de los que disponemos, es si la asamblea de Jerusalén fue el punto de partida de la misión paulina a los gentiles, o si ésta ya había comenzado. La entrada paulina en "Asia" y luego en Europa, ¿es una consecuencia de las

${ }^{14}$ Es importante tener en cuenta que el término "apóstol" tiene diferentes significaciones en los distintos autores del NT: para Pablo es "apóstol" todo aquel que se ha visto beneficiado con una manifestación del resucitado, mientras que para Lucas el término se limita a los Doce: apóstol es el testigo que "compartió con nosotros desde el bautismo de Juan hasta el día en que fue llevado de entre nosotros al cielo... testigo de su resurrección" (Hch 1,21-22); cf. L. H. Rivas, Pablo y la Iglesia. Ensayo sobre "las eclesiologías" paulinas, Claretiana - Buenos Aires - 2008, 136-140.

${ }^{15}$ El término hikanós es frecuentemente usado por Lucas; por Pablo, sólo en las cartas a los corintios. Pablo deja muy claro en 2 Cor 3,4-6 que él no está capacitado para el ministerio sino que "nuestra capacidad viene de Dios", que en el llamado lo ha hecho "capaz"; esto pone a Pablo en un esquema semejante al de los profetas, como Jeremías, que es "un muchacho". 
decisiones tomadas en la asamblea o es anterior a ésta? Los autores están divididos sobre esto; ciertamente, la fiabilidad histórica o no de Hechos influye en la toma de postura de los estudiosos. ${ }^{16}$ También parece importante tener en cuenta la "colecta" para precisar esta cronología.

C) De todos modos, lo cierto es que al término de la asamblea de Jerusalén, en Antioquía, se produce un nuevo encuentro entre Pedro y Pablo, aparentemente el tercero. Sobre estos encuentros debemos precisar al menos las dificultades con las que nos encontramos para establecer una cronología con cierta verosimilitud:

Pablo lo establece con cierta precisión: luego de recibir la revelación del resucitado e ir a Arabia, a los tres años va a Jerusalén para conocer $^{17}$ a Pedro [primer encuentro]. Sólo permanece quince días y se dirige a Cilicia y Siria (Gal 1,18-21). Catorce años después (¿después de qué?), vuelve a Jerusalén "movido por una revelación", y les expone "en privado" el Evangelio a los "notables" (2,1-10 [segundo encuentro]). Luego de esta asamblea, vuelve a Antioquía donde por tercera vez encuentra a Kefas y se produce el conocido conflicto (2,11-14). Sin embargo, esto deja varios temas en la "nebulosa", como podemos verlo en la misma carta a los Gálatas:

1. Pablo predica a los gentiles, ¿desde el comienzo de su vocación, desde la asamblea de Jerusalén o desde qué momento? La frase "que lo anunciase entre los gentiles" $(1,16)$, ¿debe entenderse en sentido personal o territorial (anuncio en territorio gentil)? ¿Se refiere a lo que Pablo entendió en el momento de la revelación o a lo que interpreta al escribir la carta?

2. Si predica a paganos desde el comienzo, ¿habló del tema con Kefas en la primera visita después de ir a Arabia?

3. Si -en cambio- predica a partir de la asamblea, ¿a qué se refiere cuando dice "saber si había corrido en vano" $(2,2)$ ?

${ }^{16}$ Ya hemos señalado los diferentes viajes de Pablo a Corinto y su relación con Hch, y haremos referencia a la posibilidad de una visita a Corinto de Pablo y Bernabé, probablemente anterior a la asamblea. Ciertamente, es sólo una posibilidad, pero no ha de descartarse.

${ }^{17}$ Como veremos, este tema será muy importante para entender el ministerio petrino para Pablo. 
4. Si la predicación a los gentiles - sin exigir la circuncisión- provoca conflictos, ¿a qué se refiere cuando afirma que las Iglesias de Judea "glorificaban a Dios por mi causa" $(1,24)$ ?

5. ¿Cuándo y dónde se han introducido los "falsos hermanos" $(2,4)$ ?

6. ¿Qué rol jugó la comunidad de Antioquía (y Bernabé) en la predicación a los paganos y su recepción en la Iglesia sin exigir la circuncisión?

7. ¿Cuánto de preciso o estricto tiene la frase "nosotros a los gentiles y ellos a los circuncisos" $(2,9)$ ? ¿Pablo dejó de predicar a judíos? ¿Kefas (y las demás "columnas") no predicaban a paganos?

Todos estos temas, y otros más, se prestan a muy variadas lecturas e interpretaciones, y es difícil elaborar con precisión un desarrollo histórico en base a tantas hipótesis. ${ }^{18}$ De todos modos, para nuestra intención, es importante intentar precisar sólo un elemento: el texto de Gal 2,7-8, ¿a qué se refiere con exactitud? ¿Pablo narra la escena de la asamblea? ¿Es una interpolación? ¿Es una cita de una suerte de "decreto de la asamblea"? Hay muchos indicios para pensar que el texto no es paulino:

El primer indicio es el uso del nombre Pétros, para aludir a Pedro, siendo que Pablo siempre utiliza Kefas, como hemos dicho; esto se une al hecho de que antes y después el texto refería a los notables/columnas, que son Santiago, Kefas (¡en segundo lugar!) y Juan y también a Pablo y a Bernabé (y Tito). En cambio, en este texto todos los demás -salvo Pablo y Pedro- han desaparecido. En segundo lugar, el verbo energeîn, frecuente en Pablo, se usa aquí de un modo sin paralelo ni en Pablo ni en el resto del NT (seguido de dativo sin preposición). También parece nopaulino el uso de "Evangelio" como aquí se presenta: "evangelio de la circuncisión / de los incircuncisos". Lo mismo puede decirse del uso de "apóstol de los circuncisos". Por esto, ya desde hace tiempo (W. C. van Manen, 1887) se ha propuesto que el texto es interpolado, o posteriormente (O. Cullmann, 1952), que Pablo cita un "protocolo". Ambas posiciones tienen quienes las sostienen en nuestros días, ${ }^{19}$ aunque

18 "Algunos eventos prometen clarificación y resolución pero de hecho son sólo ocasión de nuevos conflictos", U. SChnelle, Apostle Paul. His Life and Theology, Baker Academic - Michigan - 2005, 121.

${ }^{19}$ Afirma que se trata de una interpolación: W. O. WALKER, "Galatians 2,7b-8 as a Non-Pauline Interpolation", CBQ 65 (2003) 568-587 (sigue fundamentalmente a E. 
también otros reconocen el pasaje como paulino. ${ }^{20}$ Lo cierto es que no es fácil sostener o negar la autenticidad del fragmento sin que queden a su vez interrogantes por resolver.

Otro elemento interesante de saber para entender la relación entre Pablo y Pedro -aunque seguimos en el terreno de las hipótesis-, es si Kefas pasó o no por Corinto. En 1 Cor encontramos tres claras referencias a su persona: la existencia del "partido de Kefas" $(1,12)$, la alusión a que Kefas viaja acompañado de "mujer hermana" $(9,5)$; y la aparición del resucitado "primero a Kefas" (15,5), que ya hemos señalado. Las dos primeras alusiones permiten preguntarnos si es que los corintios han visto a Kefas viajando con su esposa, y si el partido que lleva su nombre existe por alguna relación personal entre un grupo corintio y el Apóstol. Afirmar, como lo hace Vielhauer, que Pedro pasa por Corinto camino a Roma, no pasa de lo meramente hipotético. ${ }^{21}$ Afirmar, como se hace desde Reitzenstein ${ }^{22}$ y la Religionsgeschichte, que la relación es semejante a lo que ocurre con los thíasoi de las religiones de misterios que establecen una estrecha relación entre el iniciador y el iniciado -en este caso, la relación de cada grupo con su referente tendría que ver con el bautismo-, es también algo hipotético: no parece tener en cuenta que Pablo afirma no haber bautizado casi a ninguno y que así no se explica el "partido de Cristo".

La existencia del "partido de Kefas" no necesariamente indica su presencia en Corinto, aunque esta posibilidad no pueda excluirse. Es

Barnikol, 1931). Que se trata, en cambio, de un decreto lo sostienen A. SCHMIDT, “Das Missionsdekret in Galater 2,7-8 als Vereinbarung vom ersten Besuch Pauli in Jerusalem", NTS 38 (1992) 149-152; J. Murphy-O'ConnOR, Paul. A Critical Life, Oxford - 1996, 93-94. Ambos piensan en un decreto anterior a la asamblea. Anteriormente, Cullmann había sostenido que Pablo alude a un decreto de la asamblea de Jerusalén. Un buen análisis, paso a paso, de la vida de Pablo desde su "conversión" a la "asamblea de Jerusalén", puede verse en A. BunINE, "Paul: 'Apôtre des Gentils' ou... 'des Juifs d'abord, puis des Grecs'?", ETL 82 (2006) 35-68: sostiene, fundamentalmente, que la predicación a los paganos es algo que Pablo comienza a llevar a cabo muy poco antes de la asamblea de Jerusalén.

${ }^{20}$ Por ejemplo, sostiene que es paulino R. TREVIJANo, "Los primeros viajes de San Pablo a Jerusalén (Gal 1,18-20 y 2,1-10)", Estudios Paulinos, Plenitudo Temporis 8, Universidad Pontificia de Salamanca - Salamanca - 2002, 31-69 (original de 1995); sostiene que desde su "cristofanía", Pablo predica a paganos, pero que la asamblea de Jerusalén debe ubicarse antes del primer viaje misional. Una presentación -y breve bibliografía- de diferentes posiciones en nuestros días se puede ver también en SCHNELLE, Apostle Paul, 127 n. 19.

${ }^{21}$ Ph. Vielhauer, "Paulus und die Kephaspartei in Kor", NTS 21 (1975) 341-352.

22 R. ReITZENSTEIN, Die hellenistischen Mysterienreligionen, Stuttgart - $1927^{3}$. 
evidente la presencia de Pablo y la de Apolo en la ciudad, pero eso no implica incuestionablemente la de Pedro. Bien pueden remitir a su persona, o a lo que conocen de ella, o a que lo han conocido en otra parte. Se ha señalado - con probabilidad- que el "partido de Kefas" estaría conformado por el conjunto judeo-cristiano de la comunidad. Por otro lado, la alusión al viaje de Kefas y de otros con "mujer hermana" no implica que haya estado en Corinto, sino sólo que es conocida esa costumbre, como se alude a que también lo hacen "los demás apóstoles, los hermanos del Señor y Kefas" $(9,5)$; y en seguida también se refiere a Bernabé, que no sabemos si estuvo o no en Corinto. ${ }^{23}$ Concluyamos, entonces, que -aunque no podamos descartarlo- no hay elementos seguros para afirmar que Kefas estuvo en Corinto.

Queda finalmente la duda sobre en qué momento Pedro viaja a Roma, ya que ni la carta a los Romanos ni Hechos de los Apóstoles permite inferir un encuentro entre ambos en la capital del imperio. De todos modos, aunque el encuentro hubiera tenido lugar, éste habría sido posterior a los escritos paulinos y no está consignado en ellos, por lo que el tema queda fuera de nuestra investigación.

Para concluir esta primera parte, entonces, podemos afirmar que los elementos históricos más probables para referirnos al encuentro histórico entre Saulo y Kefas debemos encontrarlos en la carta a los Gálatas. Mirando esto podremos preguntarnos cómo entiende Pablo a Pedro y su ministerio.

\section{La mirada de Pablo sobre la figura y ministerio de Pedro}

Después de haber ubicado los encuentros personales entre Pedro y Pablo, podemos dar el siguiente paso y dejar a Pablo hablar sobre Pedro.

\subsection{Pedro en 1 Corintios}

1. Es útil comenzar por el texto kerigmático de 1 Cor 15,5-11: allí Pedro es mencionado el primero y, luego de una serie, Pablo es

${ }^{23}$ La presencia de Bernabé en Corinto sería posible si suponemos un primer viaje misionero conjunto de Pablo y Bernabé por Europa antes de la Asamblea de Jerusalén y del conflicto de Antioquía. Como hemos señalado, es posible, pero siempre quedamos en el terreno de lo hipotético. 
nombrado el último ${ }^{24}$ (1 Cor 15,5-8). Ciertamente, en el esquema cultural, eso no es inocente: ejemplos evidentes son las listas de los Doce de los Evangelios, en las que siempre Pedro es nombrado en primer lugar y Judas en el último (Mt 10,2-4; Mc 3,16-19; Lc 6,14-16; cf. Hch 1,13). De hecho, Pablo se pone en el último lugar no por el ésjaton, ya que acota ser el más insignificante (elájistos) ${ }^{25}$ de los apóstoles, no capacitado (hikanós) para ser llamado 'apóstol' por haber perseguido a la Iglesia, pero capacitado por la gracia que trabaja "conmigo" (sỳn emoi).

En 2 Cor 3,5-6 Pablo vuelve sobre el tema de la "capacidad": "Y no es que por nosotros mismos seamos capaces (hikanoi) de considerar cosa alguna como propia; por el contrario, nuestra capacidad (hikanótēs) procede de Dios, quien nos ha capacitado (hikánōsen) como servidores (diakónous) de la nueva alianza". Para Pablo, la capacidad es la de ser ministros (2 Cor 3,6), "apóstol" (1 Cor 15,9-10) por la gracia. Y es precisamente esa gracia, que "no se hizo vacía (kenế)" en Pablo, la que lo llevó a trabajar "más que todos ellos", pero -para que no se lo malinterprete- "no yo, sino la gracia de Dios conmigo".

Precisamente, ese trabajo de la gracia es el que le impide a Pablo, y por lo tanto también a Pedro o a cualquiera de los demás, jactarse de la obra (sea de la obra propia, sea de la obra de un referente, como el líder de un "partido"). Es la gracia lo que cuenta. Si el que se jacta no lo hace en el Señor (1 Cor 1,31; 2 Cor 10,17), su jactancia será vana, será necedad. ${ }^{26}$ Ni Pedro debe jactarse por ser el "primero", ni Pablo por

24 Aunque es probable que Pablo se vea a sí mismo como "profeta escatológico", el uso de ésjaton en esta unidad está en evidente contraposición: "primeramente" a Kefas... eîta "luego", épeita "y luego" (cada uno repetido dos veces) para concluir "finalmente" en Pablo. Si bien es posible que la referencia a Pablo como "aborto" (éktrōma) fuera usada agresivamente por algunos (C.K. BARRETT, "Cephas and Corinth", Abraham unser Vater. Juden und Christen im Gespräch über die Bibel. FS für O. Michel zum 60. Geburtstag [ed. O. Betz - M. Hengel - P. Schmidt], Brill - Leiden/Köln 1963, 4; R. PEsCH, "Pedro y Pablo", Comentario Bíblico Internacional [dir. W. Farmer], Verbo Divino - Navarra - 1999, 248), no pasa de la mera suposición el intento de determinar quiénes serían estos adversarios. Nos parece preferible pensar que Pablo usa una metáfora para expresar su llamado como "un acto radical de la gracia de Dios empoderada por el éxito de la misión", P. vON DER OSTEN-SACKEN, "'єK $\tau \rho \omega \mu \alpha$ ", etc., EDNT, I, 423.

25 No parece que elájistos deba identificarse con "pequeños" -como népios, paidion o mikrós, que pueden identificarse en Mt con los miembros de la comunidadsino como "los últimos", "los más pequeños", "los insignificantes"; cf. Mt 2,6; 5,19; 25,40.45; LC 12,26; 16,10; 19,17; 1 Cor 4,3; 6,2; 15,9; Ef 3,8; Sant 3,4.

${ }^{26}$ Hemos señalado en E. DE LA SERNA, "La justificación por la fe. Una mirada teológica del trabajo paulino" RevBib 68 (2006) 110-111, que "jactarse" es un término in- 
haber "trabajado en exceso". Todo es gracia. En el mundo en el que la preeminencia, el honor y los "lugares" son valorados -y sobrevalorados-, no es eso lo que cuenta en la novedad de los tiempos escatológicos (lo mismo dirá Pablo de los "notables" en Gal 2,6, como veremos). La gracia es lo que importa, y la respuesta en beneficio del Evangelio. Por lo pronto, podemos reconocer que el hecho de que Kefas sea "el primero" en beneficiarse con una visión del resucitado no representa para Pablo ninguna cualidad jerárquica. No está allí para él el valor o lo que da "capacidad". Esta proviene de la "pura gracia". La primacía de la fe impide establecer distinciones de personas: Pedro no es importante por ser el primero -como no es importante ser judío frente a los paganos, cf. Rom 1,16; 3,27-, o Pablo no es poco por ser el último -lo que parece ser un tema que influye en el conflicto de Galacia-, ni mucho por trabajar "en exceso más que todos" -es gracia- y lo que importa es que Cristo es anunciado, cf. Fil 1,18.

Notemos, además, que Pablo entiende por "apóstol” a todos aquellos que han "visto al Señor" y por tanto son "enviados" a anunciar el Evangelio. ${ }^{27}$ Puesto que él tiene claro que ha "visto a Jesús, Señor nuestro" (1 Cor 9,1), el apostolado de ambos tiene el mismo fundamento.

2. Fuera del texto kerigmático, Pedro es mencionado en 1 Cor al referir al partido que lleva su nombre; y porque los corintios saben que viaja con "mujer hermana" (9,5; seguramente su mujer). Como dijimos, es una posibilidad que haya pasado por Corinto, aunque no tenemos elementos que lo confirmen. Por otro lado, es evidente que su fama era ya conocida fuera de Palestina (como se ve también en Gálatas).

En 1 Cor 1,12; 3,22 Pablo alude al "partido" de Kefas. No es fácil saber qué causó la división, ni qué "sector" se encuentra representado en cada grupo. Habitualmente se afirma que el "grupo de Kefas" sería el grupo judeo-cristiano, y esto es una posibilidad. Más difícil es saber qué causa la existencia de partidos. La insistencia en el tema de la sabiduría, unida a la presentación en una sabiduría alternativa (la sabiduría de la

termedio entre "gloriarse", que siempre es bueno, y "pavonearse / hincharse" que siempre es malo. Jactarse será bueno o malo según sea el objeto de la jactancia. Sólo es bueno hacerlo si es Dios el que aparece, sea por jactarse en Dios, o porque es uno el que desaparece, por jactarse en la cruz, o en la propia debilidad.

${ }^{27}$ La identificación "apóstoles = los Doce" no parece de Pablo, y probablemente tampoco de Mc y Jn: "Es habitual hablar de "los doce apóstoles", pero esa identificación de "los doce" con "los apóstoles" se encuentra solamente en los escritos de Lucas", L.H. RIvAs, Pablo y la Iglesia, 136-137; quizá también se deba incluir Apocalipsis $(21,14)$; cf. Mt 10,2. 
cruz), hace también posible que se encuentre allí una de las causas, si no la única, de la división; en ese caso no es improbable que el origen se deba encontrar en el "partido de Apolo", lo que explicaría por qué es mencionado antes que Kefas. ${ }^{28}$ Pero por sobre todas las cosas, parece necesario destacar que Pablo no cuestiona tal o cual "grupo" sino el hecho de que los haya. No podemos coincidir con W. Schmithals cuando afirma que “...es comprensible que no haga directa mención a las críticas a sus oponentes, pero la razón puede reconocerse claramente. Siguiendo el principio de que la mejor defensa es un buen ataque, Pablo primero cuestiona a los corintios sus divisiones". 29 Pablo no defiende el "partido de Pablo" frente a los demás partidos, sino que remite, desde el bautismo, a la unidad de la comunidad. $^{30}$ Es inconcebible, para él, que la comunidad esté dividida. Y por lo mismo, hemos de decir que Pablo no critica el partido de Pedro sino -insistimos- el hecho de que haya partidos.

Es interesante notar que diferentes autores suponen que el enfrentamiento principal de Pablo, a lo largo de toda la carta (o incluso también en 2 Cor), es con alguno de estos partidos, e interpretan en ese sentido los diferentes grupos que se detectan a lo largo de la/s carta/s. Así, C. K. Barrett piensa que el gran enfrentamiento de Pablo en ambas cartas a los corintios es con el grupo de Kefas; ${ }^{31}$ por otra parte, W.

28 "Uno de estos predicadores, presumiblemente Apolo, se ha destacado por su elocuencia (ver Hech 18,24), y los que han quedado impresionados por su predicación se comportan como si constituyeran un partido enfrentado con otros", RIVAS, Pablo y la Iglesia, 121.

${ }^{29}$ W. Schmithals, The Theology of the First Christians, Westminster J. K. - Kentucky - 1997, 110-111.

${ }^{30}$ A. Descamps, "Le Baptême, fondement de l'unité Chrétienne", Battesimo e Giustizia in Rom 6 e 8 (publ. L. De Lorenzi), Serie Monografica di Benedictina. Sezione biblico-ecumenica 2, Roma - 1974, 203-234 (esp. 204-212); publicada en castellano como "El bautismo, fundamento de la unidad cristiana", RevBib 69 (2007) 31-64 (esp. 32-42).

${ }^{31}$ Lo sostiene originalmente en "Cephas and Corinth", 1-12. En realidad, para 1 Cor sigue a T. W. Manson, y es todavía menos preciso con 2 Cor (que no se puede ver "en detalle en este pequeño espacio", p. 8): "en 2 Cor no hay precisa referencia a Pedro, y los pasajes más combativos de Pablo están presentados con términos alusivos, que muestran poco respecto a los apóstoles originales de Jerusalén, pero reserva una vigorosa antipatía a otros agentes aparentemente actuantes en Corinto" (p. 12). Pero aunque los adversarios de Pablo en 2 Cor sean judeo-cristianos (cf. E. DE LA SERNA, "Segunda carta a los Corintios", Comentario Bíblico Latinoamericano, Nuevo Testamento (dir. A. Levoratti), Verbo Divino - Navarra - 2003, 860-861), ¿por qué no pueden ser "judeo helenistas", como propone G. Friedrich, "Gegner des Paulus im 2. Korintherbrief", Abraham unser Vater, 181-215; y si son "judeo palestinenses", ¿por qué no 
Schmithals ${ }^{32}$ sostiene que el enfrentamiento paulino es con el "grupo de Cristo", que en realidad es el único partido, ${ }^{33}$ y que representa el grupo gnóstico de la comunidad; ${ }^{34}$ mientras que G. Sellin ${ }^{35}$ supone que el enfrentamiento es con el "partido de Apolo".

Detengámonos brevemente en la posición de Barrett que es la que interesa a nuestra cuestión: en su comentario a 1 Cor afirma que

Pedro era el gran misionero, cabeza itinerante de la cristiandad judaica, mientras que Santiago era la cabeza residente en Jerusalén. Se puede estar prácticamente seguro de que el grupo de Pedro representaba de algún modo la cristiandad judaica...

y concluye:

No se puede considerar estos problemas (toda la historia del cristianismo primitivo) sólo sobre la base de perícopas aisladas; nos referiremos a esto a lo largo del comentario, pero se encontrará un análisis más completo en el comentario a 2 Cor. $^{36}$

En su comentario a 2 Cor, después de refutar -siguiendo a Friedrich- la probabilidad de adversarios gnósticos, como sostenía Schmithals, afirma:

Los adversarios eran ciertamente judíos. Había judíos de origen palestinense que ejercían una influencia judaizante. Esta mirada no puede ser refutada con el argumento de que Pablo, en el debate con ellos no dice nada sobre la circuncisión o el sábado. Eran judaizantes, de quienes Pedro en Antioquía (Gal

pensar en el grupo de "los de Santiago"? Suponer que el partido de Kefas represente el sector judeocristiano de la comunidad no significa necesariamente que todo elemento discordante o conflictivo con el judaísmo, o los judaizantes deba remitir a este "partido".

32 W. SChmithals, Die Gnosis in Korinth, FRLANT 66, Göttingen 1965²; ID., First Christians, 120-135.

${ }^{33}$ No se debe "(i)nferir de los cuatro slogans corintios en 1,12 cuatro partidos en Corinto que están en contención unos con otros", Ibíd., 121.

34 "(E)l término 'sabiduría' es tópico en una situación análoga en 2 Cor 1,12 (..), el término común en Corinto para el alto conocimiento perdido en Pablo es gnosis".(...) "Así vemos más claramente qué lleva a Pablo a escribir la carta: otros maestros agitan contra él con la afirmación de que ha sacado de la Iglesia la 'sabiduría' o la 'gnosis' y se ven como el verdadero evangelio (cf. 2 Cor 4,3)", IBíD., 123.127.

35 G. SelLIN, "Das 'Geheimnis' der Weisheit und das Rätsel des 'Christuspartei'(zu 1 Kor 1-4)", ZNW 73 (1982) 69-96.

${ }^{36}$ C.K. BARRetT, La prima lettera ai Corinti. Testo e commento, Dehoniane - Bologna - 1979, 61. 
$2,11)$ es el ejemplo más notable, el cual mantiene una posición legalista sin insistir sobre las expresiones que supone. ${ }^{37}$

No negaremos que haya conflictos con judeo-cristianos en 2 Cor y -menos evidentemente- en 1 Cor. ${ }^{38}$ El tema es complejo en más de un caso: p.e., los "débiles" y "acostumbrados al ídolo" (cf. 1 Cor 8,7), ¿son judeocristianos? ${ }^{39}$ Pero se debería aclarar por qué Apolo es citado antes que Kefas en la lista de partidos. Se ha propuesto que en realidad los grupos serían dos: Pablo-Apolo y Kefas-Cristo, pero todo queda en el terreno de las hipótesis. De todos modos, es importante notar, como el mismo Barrett lo hace:

Hay divisiones basadas en lealtades personales. Pablo ha escuchado por los miembros de la casa de Cloe la existencia de estas divisiones (érides) y las explica (1 Cor 1,11-12). Cada uno tiene su partido diciendo: Yo soy de Pablo, yo soy de Apolo, yo soy de Cefas, yo soy de Cristo. Las características de los cuatro grupos han sido intensamente debatidas; afortunadamente no tenemos necesidad de entrar en ese debate. Sean lo que fueren los principios o maneras de vivir, eso marca lo que los grupos pueden ser. Quienes adhieren a ellos, se adhieren ellos mismos a las personas. No se debe asumir que aquellos cuyos nombres fueron usados desearan ser líderes de facciones rivales; es suficiente saber que ellos existen y que sus nombres pueden ser usados como etiquetas". 40

37 C.K. BARRETT, The Second Epistle to the Corinthians, Hendrickson - London 1973, 30.

38 "1 Corintios 1,22 menciona el partido de Pedro, y por lo que hemos escuchado, Cefas 'forzó a los gentiles a vivir como judíos' (Gal 2,14), lo cual puede hacernos leer esto como evidencia de una actividad judeocristiana en Corinto. Pero 1 Corintios en su totalidad no nos da evidencias de esto. Cefas es mencionado sin la más mínima señal de hostilidad $(1,12 ; 3,22 ; 9,5 ; 15,5)$ y lo mismo es verdad de Santiago $(15,5 ;$ cf. 9,5$)$. Fuera del contexto de la crisis de Galacia, el 'incidente de Antioquía' no parece haber sido tan formativo en la identidad apostólica de Pablo como a veces se cree. (...) por tanto no hay trazos de influencia judeocristiana y menos todavía de amenaza judeocristiana", F. Watson, Paul, Judaism and the Gentiles. Beyond the New Perspective, Eerdmans - Michigan - 2007, 151-152.

39 Puede verse una breve presentación de la discusión en R. KugELMAN, "Primera carta a los corintios", Comentario Bíblico "San Jerónimo" (dir. R. Brown et al.), Cristiandad - Madrid - 1971, IV, 42; en cambio, en la nueva edición, J. MURPHY-O'CONNOR, "The First Letter to the Corinthians", The New Jerome Biblical Commentary (dir. R. Brown et al.), Prentice Hall - New Jersey - 1991, 806, afirma: "los gentiles convertidos no han asimilado todavía su conversión intelectual al monoteísmo".

${ }^{40}$ C.K. BARRett, "Eidôlothyta Once More", On Paul. Essays on His Life, Work and Influence in the Early Church, T\&T Clark - London/New York - 2003, 28-29 (la cursiva es nuestra). La misma idea con respecto a cada grupo destaca W. SCHRAGE, "Exkurs: Die korinthischen 'Parteien', Der Erste Brief an die Korinther, EKK VII/1: 1 Kor 1,1-6,11, Bensiger /Neukirchener - Zürich - 1991, 142-152. 
Por tanto, nos parece posible afirmar que no sólo Pablo no enfrenta a tal o cual grupo, y por tanto no enfrenta al partido de Pedro, sino que cuestiona el hecho mismo de la división. Y también que, así como Pablo bien sabe que él no es responsable ni avala al "partido de Pablo" ("¿Acaso Pablo fue crucificado por ustedes? ¿O han sido bautizados en el nombre de Pablo?", 1,13), nada hace suponer que Kefas avale el suyo. ${ }^{41}$

3. La última referencia a Kefas la encontramos en 1 Cor 9,5: “¿no tenemos derecho (exousían) ${ }^{42}$ a llevar con nosotros (periágein) una mujer $^{43}$ hermana $^{44}$ así como los apóstoles y los hermanos del Señor y Kefas?"

Ya hemos señalado que es posible que Pedro haya estado en Corinto, y lo haya hecho con su mujer, viviendo "a costa" de la comunidad según el dicho del Señor (cf. 9,14). Tampoco es improbable que Pablo haya estado con Bernabé en un primer viaje a Corinto, si no aceptamos la cronología de Hechos. Sería posible preguntarnos si la conclusión de la asamblea, como Pablo la narra: "nosotros a los gentiles y ellos a los circuncisos" (Gal 2,9), no haría improbable el paso de Pedro por Acaya. Pero no es evidente que el eventual paso de Pedro sea posterior a la Asamblea de Jerusalén, ni que Pedro no haya ido nunca a predicar a judeo-cristianos (que luego se auto-proclamaran "partido de Kefas", por ejemplo), o que la división de tareas no haya que entenderla tan estrictamente. Sobre este texto volveremos.

${ }^{41}$ Sobre lo que significa la confianza en predicadores o en la "calidad" de la predicación por sobre la Cruz, hemos hecho referencia en "La idolatría en 1 Corintios. ¿Una clave de interpretación?", "Testigos... y servidores de la Palabra" Lc 1,2. Homenaje a Luis Heriberto Rivas (eds. V.M. Fernández - C.M. Galli), San Benito - Buenos Aires 2008, 128-131.

42 El tema del "derecho", "posibilidad", "libertad" es un tema central en esta unidad de 1 Cor.

43 Algunos autores suponen que "mujer" debe entenderse siempre como "esposa". Particularmente si siguen la versión de algunos manuscritos occidentales, F, G, y Tertuliano, Ambrosiaster y Pelagio que leen "mujeres" (gynaîkas) y omiten "hermana". De todos modos, la mayoría textual a favor de "mujer (predicativo) hermana" es abrumadora: conviene leer "una hermana como mujer", o "una mujer que sea hermana". Queda fuera de cuestión la pregunta acerca de si Pablo era casado -como sostienen Tertuliano y Clemente de Alejandría- o no lo era.

44 Muchos autores traducen "hermana" por "cristiana", lo que parece correcto; aunque no se entiende por qué en ese caso no se traduce "hermano" por "cristiano". Sobre el sentido de "hermana" hemos comentado en E. DE LA SERNA, "El lugar de la mujer en los escritos de Pablo", "Donde está el Espíritu está la libertad". Homenaje a Luis Heriberto Rivas con motivo de sus 70 años (coords. J. L. D'Amico - E. de la Serna), San Benito - Buenos Aires - 2003, 406. 
Por cierto, la lista que da Pablo nos permite ver la "rica actividad misionera de la Iglesia primitiva" ${ }^{45}$ La referencia a "apóstoles" en general -lo hemos dicho- alude a un número indeterminado, aunque ciertamente bastante mayor que doce, y la referencia a los "hermanos del Señor", y no sólo a Santiago, también extiende el número. ${ }^{46}$ Que dentro de este grupo amplio sólo mencione explícitamente a Kefas ciertamente es indicio de la importancia que éste tiene. ${ }^{47}$ Es verdad que Pablo toma distancia de su praxis quedando (mónos) junto con Bernabé del lado de los que trabajan. ${ }^{48}$ Pablo parece hacer una "militancia" de su trabajo manual, reconoce el derecho del Apóstol a ser mantenido, pero quiere que ese mismo trabajo sea visto como un "sacramento" de la gracia, de aquella debilidad en la que es posible jactarse, de la gratuidad. No parece que Pablo cuestione a quienes hacen uso del derecho de no trabajar, sino que en la comunidad hay quienes cuestionan a Pablo por no hacerlo. Si quienes lo cuestionan son los del "partido de Kefas" no lo sabemos con una mínima certeza, y -si lo fueran- nada invita a pensar que Pablo aluda a Kefas por esto, precisamente porque nada compromete a Kefas con su "partido".

\subsection{Pedro en Gálatas}

Mirando la carta a los Gálatas, vemos que Pablo menciona a Kefas en tres ocasiones, todas ellas en la apología autobiográfica de 1-2: con motivo del primer viaje del "Pablo cristiano" a Jerusalén; con motivo del "segundo viaje"; y a raíz del viaje de Pedro a Antioquía después de la Asamblea de Jerusalén.

1. En un claro contraste entre el v. 17: "no subí" y el v. 18 "subí", Pablo destaca el sentido de esta "subida" a Jerusalén. ${ }^{49}$ El sentido en este movimiento está dado por historêsai Kefân (Gal 1,18).

${ }^{45}$ H. Conzelmann, 1 Corinthians, Hermeneia, Fortress - Philadelphia - 1975, 153.

${ }^{46}$ La lista de los "hermanos del Señor" en Mc 6,3 es de 4 miembros. Sin embargo, Santiago parece asentarse en Jerusalén. No sabemos si los otros eran misioneros itinerantes, o sólo misioneros por Palestina, pero el tema parece conocido por los corintios.

47 BARRETt, Prima lettera, 255, afirma que sería difícil saber por qué menciona a Cefas si no es porque visitó Corinto. Quizá "fueron 'los de Cefas' los que pusieron en duda el apostolado de Pablo", que es el tema que motiva la unidad $(9,1-3)$.

${ }^{48}$ Sobre el trabajo paulino hemos escrito en DE LA SERNA, "Justificación", 101-115.

${ }^{49}$ H. SCHLIER, La carta a los Gálatas, BEB 4, Sígueme - Salamanca - 1975, 73; R. Y. FunG, The Epistle to the Galatians, NICNT, Eerdmans - Michigan - 1994, 74. 
Ciertamente el sentido que se le dé al término historêsai influirá en la intención que descubriremos en Pablo, ya que "no subir" y "subir para..." denota una intención; por algo Pablo "no sube" y, por algo, luego "sube" a Jerusalén. Y la razón de este segundo movimiento está dada por el verbo historêsai.

Con clarísima intención apologética, Pablo destaca su independencia en el ministerio: "no de hombre" (1,1.11-12), esa parece la razón explícita para que destaque que "no subió" hasta pasados tres años. Ciertamente Pablo no quiere presentar su ministerio como "dependiente" de Pedro, ni de ningún otro.

Los comentarios varían entre las diferentes traducciones propuestas del verbo historéō: "ver" [KJV; Lutero 1545; Betz], "conocer" [TOB; LBA; BA; NBE; BPeregr; BJ3; Hofius], "visitar" [BJ; CastilianB; NVI; LPD; Schlier; Martyn; Pitta], "informarse" [NASB, Kilpatrick, Verseput, Dunn.$^{50}$

Señalemos que, gramaticalmente, todas las opciones son posibles, pero difícilmente Pablo lo diría en el sentido de "ser enseñado por" dado el carácter apologético de la carta que hemos señalado; pero tampoco parece que deba entenderse como una mera visita de tipo "turístico". ${ }^{51}$ Es casi un lugar común de muchos comentaristas, desde Dodd hasta nuestros días, afirmar que obviamente Pedro y Pablo "no hablaron del clima". 52

En un artículo, Hofius destaca que historêsai no puede ser entendido en el sentido clásico de "tomar información de", como propone Dunn; ni tampoco como "visitar a", sino probablemente como "conocer

${ }^{50}$ La búsqueda de un trasfondo rabínico lleva a W. D. DAVIES a suponer una "con-

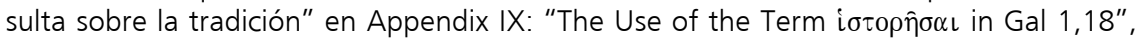
The Setting of the Sermon on the Mount, Cambridge University - London/New York/Melbourne - 1964, 1977, 453-455. Piensa que el trasfondo debe ser rabínico, ya que Pablo usa Kefas y no Pedro, no teniendo en cuenta -como lo hemos dicho- que (casi) siempre Pablo llama así a Pedro. Algunos manuscritos -especialmente occidentales- prefieren "Pedro", pero parece preferible mantener "Kefas" por razones textuales (lectio difficilior).

${ }^{51}$ En algunos pocos manuscritos de Hch 17,23 se utiliza historêsai para señalar que Pablo "vio", "visitó", los monumentos de Atenas.

52 E. LOHSE, "St. Peter's Apostleship in the Judgment of St. Paul, the Apostle to the Gentiles. An Exegetical Contribution to an Ecumenical Debate", Gr. 72 (1991) 427, n. 11 (irónicamente, acota Lohse: "algo que no es en ningún momento y lugar algo de real interés para discutir en una tierra donde el clima es normalmente bastante estable"). 
a". Dunn le responde: conocer a Kefas para obtener información de él. ${ }^{53}$ Más tarde, este mismo autor lo resume de esta manera:

Por cierto, no podemos estar seguros cuándo estuvo Pablo en Jerusalén, pero la cronología más probable de su vida hace ciertamente posible, incluso probable, que Saúl de Tarso haya estado en Jerusalén por lo menos durante algún tiempo del ministerio de Jesús. Difícilmente podría ignorar informes y rumores sobre su enseñanza y sus actividades. Pero aun cuando nosotros no podamos construir demasiado sobre tal especulación, existe la probabilidad de que Pablo haya recibido instrucción (de parte de los creyentes de Damasco) después de su conversión (cf. 1 Cor 15,1). Y todavía más, tenemos el propio testimonio de Pablo que pasó quince días en Jerusalén "para conocer a Cefas [Pedro]" (Gal 1,18). Esto sucedió unos dos o tres años después de la conversión de Pablo, es decir, aproximadamente sólo cinco años después del final del ministerio de Jesús. Una vez más, es difícil dudar que sus conversaciones nunca -o sólo raramente- hayan tocado el ministerio anterior a la pasión de Jesús. Al contrario, "lograr conocer" a Pedro debe haber incluido "lograr conocer" el papel de Pedro como el discípulo principal de Jesús durante su ministerio en Galilea. De no menor importancia lo habría sido para Pablo, si él tuviera conocimiento anterior de Jesús, confrontar sus primeras impresiones, informado por el testigo con más autoridad. ${ }^{54}$

Pablo remite a la tradición en algunas ocasiones, aunque no es fácil saber cuánto de esto recibió en Damasco (¿1 Cor 15,1-8?) y cuánto, más tarde, en Antioquía (¿1Cor 11,23-26?); pero es cierto que no pretende ser él el "origen y fuente" sino un eslabón en una cadena en la que Pedro ocupa un lugar principal. Podemos también preguntarnos por qué Pablo busca a Pedro y no a toda la Iglesia de Jerusalén, pero no es improbable que la contraposición de Pedro con Pablo haya sido introducida en Galacia por los maestros judaizantes. ${ }^{55}$ De todos modos, acota que no vio a ningún otro apóstol. La comparación con Santiago (notemos que a

53 J.D.G. DuNN, "The Relationship between Paul and Jerusalem according to Galatians 1 and 2", recopilada en Jesus, Paul and the Law. Studies in Mark and Galatians, J. Knox/Westminster - Louisville/Kentucky - 1990, presenta su opinión (originalmente de 1981) sobre el encuentro de Pedro y Pablo. En 110-113 da su opinión sobre el sen-

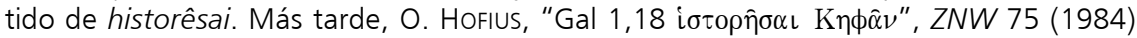
73-85, destaca que el término no debe entenderse en el sentido clásico. Esto lleva a

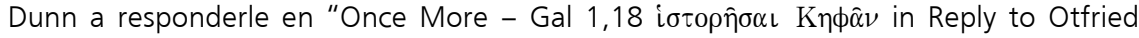
Hofius", ZNW 76 (1985) 138-139. En Jesus, Paul and the Law, 127-128, Dunn presenta también su respuesta a Hofius.

54 J.D.G. DunN, The Theology of Paul the Apostle, T\&T Clark - Edinburgh - 1998, 188 (la idea es idéntica, incluso literalmente, a lo dicho en "The Relationship", 113.

55 J.L. MARTYN, Galatians, AB 33A, Doubleday - New York - 1997, 172. 
Pedro lo busca, a Santiago, lo vio ${ }^{56}$ ) también puede estar marcada por el conflicto con los judaizantes. Pero también debemos tener en cuenta que con Pedro permanecerá ¡sólo 15 días! Difícilmente debamos entenderlo en el sentido de que quien ya ha predicado por dos o tres años, y se sabe instruido por Jesucristo, necesite ser enseñado por Kefas, y lo logre en tan poco tiempo. Seguramente, la traducción de historêsai debamos buscarla en una traducción intermedia entre "ser enseñado por" y "visitar a". "Conocer" parece ser una buena opción, especialmente dada la diferencia con "ver" (a Santiago). ${ }^{57}$

El segundo encuentro de Pablo con Kefas ocurre "al cabo de catorce años". No afecta a nuestro tema saber catorce años después de qué. Lo cierto es que Pablo narra aquí lo que se ha llamado "la Asamblea de Jerusalén", y lo que allí se decidió. Como se ha dicho en la primera parte, muchos temas quedan en la nebulosa a nivel histórico. De todos modos, debemos intentar profundizar la relación Pedro-Pablo a partir de este texto.

En Gal 2,1-10 Pablo se encuentra a solas con los dokoûntes ("los reputados", "considerados", vv. 3.6.9) y confronta con ellos su "Evangelio", la "verdad". Pero en clara confrontación con un grupo al que llama falsos hermanos (pseudadélfoi) de los cuales afirma taxativamente también que actúan secretamente (pareisaktoi), se escurren, infiltran (pareisêlthon), espían (kataskopêsai) pretenden esclavizar (katadoulósousin). Sin dudas para Pablo nada tienen que ver los "notables" con los "falsos hermanos", aunque pudiera ser que éstos pretendieran aludir a alguno de aquéllos. La "libertad", la "verdad del

56 Sólo "incidentalmente", acota R. PESCH, "Peter in the Mirror of Paul's Letters", Paul de Tarse. Apôtre du notre temps. De la communauté monastique de S. Paul en memoire de Pape Paul VI (dir. L. De Lorenzi), Rome - 1979, 290-309, 302.

${ }^{57}$ F. MUBNER, Der Galaterbrief, HThKNT 9, Herder - Freiburg/Basel/Wien - 1981, 94 (y remite a H. SChlier, Gálatas, 74; y a O. CulLMAnN: "Es verdad que este [i.e., conocer a Pedro] fue el único motivo de su viaje. Obviamente sabe que este hombre estaba a la cabeza de la comunidad", "П'́є $\rho \varsigma^{\prime}$, TDNT, VI, 109); matiza ligeramente, y de un modo quizás anacrónico, por obvio, A. PITTA, Lettera ai Galati, SOC 9, Dehoniane Bologna - 1996, 102: "podemos afirmar que Pablo visita con referencia y disponibilidad a la cabeza de la Iglesia de Jerusalén. Esta implicación todavía no debe hacer pensar en un reconocimiento del primado petrino respecto de la Iglesia "universal'". La diferencia entre historêsai y eîdon queda bien destacada por Kilpatrick, "Galatians 1,18

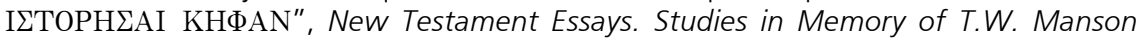
(ed. A.J.B. Higgins) Manchester - 1959, 144-149, citado por C.K. BARRETT, "Christocentricity in Antioch", On Paul, 38. 
Evangelio", son para Pablo un valor intocable a "mantener para ustedes" y sobre esto volverá en la próxima unidad.

Al presentar quiénes son estos "notables", los menciona: "Santiago, Kefas y Juan" (v. 9) ${ }^{58}$; también los llamará "columnas", 59 lo cual es posible que aluda al templo escatológico. ${ }^{60}$ Es verdad que Pablo acota que "no le importa que lo sean" (v. 6), pero no puede dejarse de lado el contexto polémico de la carta para la justa comprensión de esta frase. Parece que esto debe entenderse en el mismo sentido que ya hemos señalado: no es la precedencia, "jactarse", o el "cargo", sino la gracia lo que cuenta; la iniciativa de Dios, y la respuesta manifestada como “acción de Dios". Una vez más, Pablo parece manifestarse crítico a los valores de "honor y vergüenza" con que se guía su ambiente sociocultural. Y difícilmente pueda sostenerse que Pablo niega que los "notables" tengan respeto a la libertad del Evangelio ya que se ha reunido con ellos, aparte de los falsos hermanos, precisamente por eso; de estos últimos sí se puede afirmar que Pablo no los tiene en cuenta en la valoración que hagan de su evangelio. ${ }^{61}$ Ciertamente, como señala Dunn:

Pablo niega enfáticamente que necesite apoyo de estos "falsos hermanos" -esto hubiera representado un inaceptable acto de sumisión, en parte por la posi-

58 Notar el orden, que "difícilmente sea accidental en un texto como este",

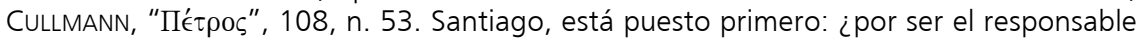
de la Iglesia de Jerusalén, o por su prestigio entre los adversarios de Pablo en Gal (en ese caso, la referencia a que sólo "vio" a Santiago sería irónica)? Ambas parecen las razones según Schlier, Pitta, Mußner.

59 SCHLIER, Gálatas, 81-82, propone que "las columnas" son un grupo más peque-

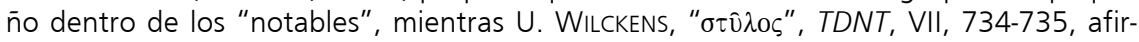
ma que son los mismos.

60 H. SHANKS - B. WITHERINGTON III, The Brother of Jesus, Harper San Francisco 2003,119-120; MARTYN -siguiendo a R.D. Aus- piensa que es posible que aluda a estos tres como "nuevos patriarcas" ya que en la tradición rabínica se refiere a Abraham,

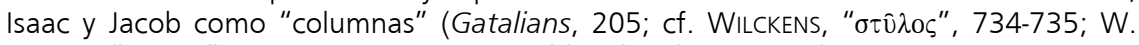

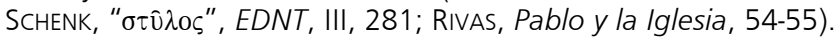

${ }^{61}$ M.D. NANOS, "Intruding 'Spies' and 'Pseudo-Brethren': The Jewish Intra-Group Politics of Paul's Jerusalem Meeting (Gal 2,1-10)", Paul and His Opponents (ed. S.E. Porter), Brill - Leiden - 2005, 62 afirma que "no obstante [la intención de Pablo de hablar a solas con los "notables", los pseudo-apóstoles], lograron entrar e hicieron conocer su opinión". Sin embargo, acota: "estos pseudo-apóstoles estaban en desacuerdo tanto con Pablo como con los apóstoles". Su propuesta es que se trata de judíos no cristianos (como también lo afirma Schmithals). Sobre el término "notables", 86, sostiene que Pablo lo usa retóricamente con un doble sentido que el lector debe descubrir, sea éste referido a los apóstoles, sea referido -irónica y sarcásticamente- a los pseudo-apóstoles. 
ción que ellos sostenían, y en parte porque no eran apóstoles- pero nada dice de rechazar la obediencia a los apóstoles de Jerusalén. ${ }^{62}$

Ya hemos señalado que la "desaparición" de dos de los notables (Santiago y Juan), y del/los compañero/s de Pablo (Bernabé ¿y Tito?), sumada al uso de "Pedro"63 en lugar de "Kefas", y algunas formulaciones que Pablo no suele utilizar han hecho a muchos pensar que el texto de Gal 2,7-8 pertenece en realidad a un texto no paulino, quizá parte del "decreto de la Asamblea". ${ }^{64}$ Sea lo que fuere, es interesante -en especial para el conflicto con los judaizantes- que Pablo se pone "en paralelo" con Pedro (y no con Santiago), y que este paralelo se asemeja a un "paralelo nada menos que" con Pedro y no un paralelo conflictivo: "se habría reconocido que Pablo era igual que Pedro, y se dividieron entre ellos el campo de trabajo misionero". ${ }^{65}$

También es preciso comprender en qué sentido debe entenderse la frase "no sea que corro o que he corrido en vano". Lo que hemos señalado indica que Pablo está dispuesto a escuchar, pero no cualquier cosa. El uso del verbo "obligar", "forzar", que Pablo utiliza en v. 3 (anagkázō) parece ser importante en la unidad. Volvemos a encontrarlo en un sentido semejante en 6,12 referido a los que "obligan a circuncidarse", y finalmente en 2,14 referido a Kefas que con su actitud, según Pablo, "fuerza a los gentiles a judaizar". Es importante que en los tres casos se refiere a una incorporación forzada al judaísmo, aunque evidentemente la primera $(2,3)$ y la última $(6,12)$ revelan que los sujetos son diferentes ya que Tito "no fue forzado a circuncidarse" mientras que

62 J.D.G. DunN, Jesus, Paul and the Law, 120.

${ }^{63}$ En Gal 2,9, D (s. VI), F (s. IX), G (s. IX), 1175 (s. XI) ponen Pétros kaì lakóbos, pero la variante parece influenciada por la teología posterior.

64 J.A. FITZMYYR, quien también cree posible que Pablo esté citando un decreto de la Asamblea al usar "Pedro" en lugar de "Kefas", piensa que "no debe tomarse en serio la opinión" de los que niegan que Kefas sea un personaje diferente de Pedro, "Aramaic Kephā' and Peter's Name in the New Testament": To Advance de Gospel. New Testament Studies, Eerdmans - Michigan - 1998², 112-124, 114-115 (puede verse la lista de estos autores en 121, n. 15). LOHSE, "Peter's Apostleship", 428, propone que Pablo usa "Pedro" ya que debe "demostrar a la audiencia greco-parlante que ambos eran apóstoles de autoridad comparable y del mismo rango". Nos parece extraña la opinión de aquellos que sostienen que Pablo prefiere en uso de Kefas porque lo reconoce como "piedra" de la Iglesia: "indica el rol extraordinario de Pedro que debe ser la roca sobre la que se funda la Iglesia", S.A. PANIMOLLE, "L'Autorité de Pierre en Ga 1-2 et Ac 15", Paul de Tarse, 274. Esto parece leer a Pablo a la luz de Mt 16, que refleja una tradición posterior.

65 J. A. Fitzmyer, "Carta a los Gálatas", Comentario Bíblico "San Jerónimo", III, 606; ID., "Galatians", New Jerome Biblical Commentary, 784. 
los maestros judaizantes de Galacia "los fuerzan a circuncidarse". El primer grupo parece referir a los notables (no entendidos irónicamente, si es el caso) entre los que se encuentra Kefas. En ese sentido queda por aclarar, más adelante, esta aparente contradicción entre su actitud de "no forzar" y "forzar" a judaizar con su actitud en la mesa. Lo cierto es que la referencia a Tito tiene su importancia. Pablo y Bernabé llevan con ellos un incircunciso, lo que confiere una fuerte carga simbólica -y quizás también provocativa- a su presencia. Sin embargo, "no fue forzado" a circuncidarse. ${ }^{66}$

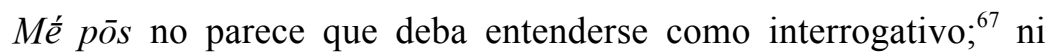
tampoco "a ver si se atreven..." ${ }^{68}$ Como sostiene la mayoría de los autores, parece que debe entenderse como "no sea que", "no fuera que"... (cf. 1 Cor 9,27; 2 Cor 2,7; 9,4; 11,3; 12,20; Gal 4,11; 1 Tes 3,5) lo que expresa un marco de temor. Lo que no es evidente, es si ese temor es presente (es decir, por lo que puedan hacer los gálatas "ahora", Pitta) o pasado (lo que hubieran dicho los "notables", Martyn); o si es temor a los falsos hermanos (a la influencia de sus intrigas, Brown) o a los "notables"; o a la falta de respuesta de los gálatas (cf. 4,11). Es interesante que cuando habla de "correr" utiliza a la vez el pasado (aoristo, édramon) y el presente (tréjō). Sin dudas que el objetivo de Pablo es presente. Puede reflejar tanto el presente, como la oposición que pudo haber tenido en el pasado: "su narración de los acontecimientos de Jerusalén le provee la ocasión de destacar que en tal encuentro el evangelio proclamado fue reconocido como no vano, con lo que las presentes dudas de los gálatas no tienen fundamento". ${ }^{69}$

El uso del término "correr" también se ha prestado a diferentes lecturas... ¿Necesariamente debe entenderse como tomado del ambiente helenista? Su uso en Josefo (Ap 2, 217-218; Ant 8,208; 13,327; 17,259), y -especialmente- en Qumrán (1QS 4,6-8) nos permiten entenderlo como una metáfora más universal para aludir a la vida (cf. 5,7a: "ustedes corrían tan bien...”). De todos modos, podemos decir:

${ }^{66}$ Algunos proponen que Tito se circuncida voluntariamente; la mayoría supone que no lo hace. No es tema que importe a nuestro objetivo.

${ }^{67}$ Así lo propone, entre otros, A. Oepke, seguido por D. GEORGI, Remembering the Poor. The History of Paul's Collection for Jerusalem, Abingdom - Nashville - 1991, 173, n. 31.

68 R.E. Brown et al., Pedro en el Nuevo Testamento, Palabra inspirada 15, Sal Terrae - Santander - 1976, 36, n. 64.

${ }^{69}$ H.D. BeTz, Galatians, Hermeneia, Fortress - Philadelphia - 1979, 88. 
La proclamación del Evangelio y el "correr" del Apóstol son aparentemente idénticos, p.e. Hch 20,24; 2 Tim 4,7. Pablo presenta su evangelio como más que una carrera. Se puede, entonces, entender la carrera como una forma de la proclamación del Evangelio. El Evangelio llega a su meta por la carrera del Apóstol. Así, cae en tierra fértil, también las comunidades a las que se dirige pueden "correr bien", p.e. 1 Cor 9,24c; Gal 5,7.70

Queda por responder el sentido del temor sobre la posible "carrera en vano". H. Schlier señala que Pablo

Está convencido, por tanto, de que no basta con haber recibido el evangelio y el apostolado por revelación de Cristo. Precisamente por ser éste con toda certeza el caso, tiene que manifestarse la unidad del evangelio y del ministerio apostólico entre él y quienes eran apóstoles antes que él. El verdadero evangelio y la legítima misión apostólica llevan en sí la tendencia a ser comunes, puesto que la iglesia se edifica sólo por el evangelio que es uno, mediante el apostolado que es uno. Mas esta unidad tiene que hacerse visible. No sólo hay que suponerlo. $^{71}$

Con cierta verdad, Betz señala que Schlier "no duda en ver en el texto las estructuras básicas de la doctrina católico-romana sobre la autoridad de la Iglesia". ${ }^{72}$ Pero es importante entender qué significa "correr en vano". Mußner entiende que Pablo se refiere a que eso es lo que plantean los "falsos hermanos". 73

Probablemente debamos coincidir con Georgi y afirmar que una lectura que dé a los "notables" tanta autoridad como para que el Evangelio de Pablo dependa totalmente de ellos, haría innecesario el cap. 1 de Gálatas $;^{74}$ pero, por otra parte, es evidente que Pablo reconoce a los "notables" una autoridad con la que dialogar y con la que "poner en consideración" el Evangelio. ${ }^{75}$

Algunos se formulan la pregunta sobre qué habría pasado si los "notables" no hubiesen aceptado el evangelio de Pablo. Pero no es fácil dar respuesta a esto: "Seguramente Pablo se habría mantenido en la

70 R. Metzner, "Paulus und der Wettkampf: Die Rolle des Sports in Leben und Verkündigung des Apostels (1 Kor 9,24-7; Phil 3,12-16)", NTS 46 (2000) 581.

71 SCHLIER, Galatas, 83.

72 BETz, Galatians, 87, n. 282. Verdad que no debe olvidar que Betz también hace dicha lectura "no desde dicha doctrina; cf. LOHSE, "Peter's Apostleship", 433.

73 MUBNER, Galaterbrief, 103.

74 Georgi, Remembering, 172, n. 27.

75 "Poner en consideración, exponer, comunicar, declarar", traduce BDAG el término anethémēn del v. 2. 
'verdad del evangelio', como se ve en el próximo episodio (2,11-14); pero esto habría hecho temblar las raíces, pues este desarrollo habría destruido su criterio de que la única 'verdad del evangelio' de hecho lleva a una iglesia de Dios, de judíos y gentiles $(3,28 ; 6,15)$ ". ${ }^{76}$ De modo semejante:

La palabra [anatithēmi] puede significar remitir una cuestión a una autoridad con la intención de obtener, quizás no un juicio sino una opinión. ¿Qué traducción adoptar aquí? Es claro que Pablo busca una opinión [...] pero esto no significa que si Pablo hubiera recibido una respuesta negativa habría cambiado o suprimido su mensaje [...] no habría cambiado su Evangelio por un no-evangelio $(1,7)$, pero habría colocado a sus iglesias en una seria dificultad. Lo que habría hecho no lo sabemos. ${ }^{77}$

Mirando las decisiones de la Asamblea, queda por precisar en qué sentido debe entenderse la frase: "nosotros a los gentiles y ellos a los circuncisos". Ya señalamos que la predicación primero a judíos en los viajes de Pablo según Hechos parece propia de su teología, de hecho él mismo afirma que "se ha hecho judío con los judíos para ganar a los judíos” (1 Cor 9,20); por otra parte, Pedro viaja a Antioquía inmediatamente después de la asamblea, lo que también parecería contradecir el pacto. Y más aún si -como vimos, es posible- ha viajado a Corinto (y también a Roma, ¿antes?, ¿después?). Posiblemente la división de tareas sea más territorial que personal, aunque Antioquía, Corinto y Roma tenían importantes comunidades judías, por lo que sabemos. En general hay consenso en afirmar que la "carta apostólica" (Hch 15,22-29) es posterior a la Asamblea, y quizás consecuencia del problema de las mesas ocurrido en Antioquía y narrado en Gal 2,11-14. Para Pablo, la cosa no es superioridad o inferioridad sino cuidar "la verdad del evangelio". ${ }^{78}$

Como elemento central, y a modo de conclusión, podemos decir con Agourides: "la intención de Pablo no es explicar detalladamente lo

${ }^{76}$ MARTYN, Galatians, 193.

77 Barrett, "Paul and Jerusalem", 5.

78 MARTYN, Galatians, 235, n. 96: "Preguntarse por qué Pablo ahora se ve superior a Pedro (al reprenderlo cara a cara), cuando antes se mostraba inferior, es introducir una cuestión extraña al texto (R. E. Brown et al. Pedro, 37). Para Pablo la norma no es la autoridad personal sino la verdad del evangelio". 
ocurrido, sino mostrar su igualdad con los apóstoles, particularmente con los reputados". ${ }^{79}$

De modo semejante, analizando mesuradamente cada perspectiva, teología y posición en el encuentro de Jerusalén y luego en Antioquía, U. Schnelle anota: "se invocan diferentes conceptos de misión en el concilio apostólico; el concilio no une en una única visión sino que reconoce a cada una como legítima expresión de fe cristiana. Es el igual status, no la identidad de cada visión del evangelio la que fue confirmada por el concilio apostólico". ${ }^{80}$ Ciertamente "la mano en señal de comunión" (v. 9) es signo evidente de esto.

Gal 2,11-14 representa el punto culminante de nuestro trabajo, y es el "emblema" del supuesto "conflicto" entre Pedro y Pablo, y -por tantode la diferencia de teologías, o criterios. Es evidente que hay terminología dura: "me enfrenté", "era censurable", "evitarlos, apartarse", "miedo", "simulación", "no procedían rectamente conforme a la verdad del evangelio", "los fuerzas a judaizar"...

Comencemos señalando algunos elementos: como hemos señalado, la presencia de Kefas en Antioquía no significa una ruptura con la división de tareas establecida en Jerusalén: no es tema planteado en el debate. Ciertamente la comunidad de Antioquía es una comunidad mixta, con muchos judeo-cristianos y muchos pagano-cristianos. Quizás este sea el origen del problema ya que el tema no parece haberse planteado en Jerusalén: a las comunidades (mayoritariamente) paganas se dirigiría Pablo, Pedro lo haría a las comunidades (mayoritariamente) judías. Pero ¿qué hacer en comunidades "mixtas"?. No es improbable que la "carta apostólica" -como hemos dicho más arriba-tenga su origen en el intento de subsanar esta laguna después del conflicto de Antioquía. Es una hipótesis, pero parece probable.

La presencia de "los de Santiago" es menos clara: ¿se trata de personas enviadas por él o que se escudaban en él? No tenemos elementos para suponer una cosa $\mathrm{u}$ otra. Es posible que las relaciones Pedro-Santiago no fueran buenas, y que menos aún lo fueran las relaciones Pablo-Santiago, pero no tenemos elementos serios para analizar detalladamente esta cuestión. Sin embargo, no es nada

79 S. Agourides, "Peter and Paul in Antioch (Galatians 2,11-21)", The Truth of the Gospel (Galatians 1, 1-4,11) (ed. I. Lambrecht), Monographic Series of "Benedictina", Biblical-Ecumenical Section 12, Rome - 1993, 59-76, 60.

${ }^{80}$ SCHNelle, Paul, 129. 
improbable que -análogamente a lo que dijimos de los "partidos" de Corinto- "los de Santiago" sean personas embanderadas detrás de un personaje sin que eso implique necesariamente su consentimiento. Santiago acaba de aparecer en el párrafo anterior como quien estrecha la mano de Pablo en señal de comunión. Es posible que esto no implicara una aceptación de todas las consecuencias del evangelio de Pablo, pero no tenemos modo de afirmarlo con cierta seguridad. Parece también posible que algunos usaran el nombre de Santiago para reclamar determinado comportamiento que el "hermano del Señor" no exigiría.

Entrando más en detalle en el conflicto, no parece que debamos suponer ni que Pablo reconoce finalmente que Pedro tenía razón, ${ }^{81}$ ni que Pedro reconozca que Pablo la tiene, como lo indicaría su silencio (Juan Crisóstomo), ni que estuvieran "teatralizando" la situación (Jerónimo, Teofilacto), ni mucho menos - como ya lo hemos señalado- que Kefas sea un personaje diferente de Pedro. ${ }^{82}$ Pedro no ha de haber aceptado el razonamiento de Pablo, porque éste lo hubiera dicho. Pero -por otro lado- si se habla de "simular" (hypokrísei) es porque Pedro está de acuerdo con la teoría fundamental de Pablo. Podemos decir que el problema no es de "ortodoxia" sino de "no obrar conforme" (ouk orthopodoûsin). Es importante notar que no parece que ni Pedro ni Santiago tengan problema con la aceptación de los incircuncisos: ellos han aceptado que no es necesaria la circuncisión para la salvación; pero sí es distinta la actitud que asumen frente a las mesas compartidas. Parece posible afirmar que Pedro se ve a sí mismo como "representante de los judeo-cristianos y defensor de sus intereses", y entonces actúa para preservar el marco cultural; no porque esto sea fundamental para la salvación sino para cuidar a los "judeo-cristianos". Y asimismo podemos decir que por su parte Pablo no es opositor a esto así planteado:

81 J. McHugH, "Galatians 2,11-14: Was Peter Right?", Paulus und das antike Judentum: Tübingen-Durham-Symposium im Gedenken an den 50. Todestag Adolf Schlatters (19. Mai 1938) (dirs. Adolf von Schlatter, Martin Hengel, Ulrich Heckel), Mohr Siebeck - Tübingen - 1991, 319-327, presenta una breve pero necesaria ubicación en la lectura desde las Pseudo-clementinas y Marción hasta Agustín y Jerónimo (319322), y luego propone que "Pedro actuó correctamente; Pablo en su momento lo reprende, pero más tarde (cf. 1 Cor 9,20-22; Rom 14,1-3; 15,1) reconoce que Pedro tenía razón y recomienda aquel modo de obrar" (322). Nada de esto se ve en el texto de Gal. Es importante también el excursus de F. MuBNER, "Gal 2,11-14 en la historia de la exégesis", Galaterbrief , 146-167.

${ }^{82}$ Cf. Agourides, "Peter and Paul", 63-64. 
precisamente, así propone actuar frente a los "idolotitos". ${ }^{83}$ Entonces, ¿por qué el conflicto?

El desencadenante del problema ocurre en relación con la comida (¿eucaristía incluida? ${ }^{84}$ ). El problema, ¿es por las comidas rituales (kosher) o se trata de un problema más amplio relacionado con el "comer-con"? Cummings remonta el tema de las comidas a la época de la crisis macabea, y su relación con el martirio. Según él, con esto Pablo "se ubica irónicamente frente al planteo de las comidas y esto lo pone del lado del mesías martirizado". ${ }^{85}$ Siguiendo a R. Aguirre nos parece muy probable que el problema no sea sólo por la pureza ritual de los alimentos sino por la normativa de con quién se puede o no comer juntos. ${ }^{86}$ Es sabido que los judíos tienen una larga lista de alimentos ( $\mathrm{y}$ otras cosas como purificaciones, vestimentas, etc...) relacionadas con la "pureza". La casa de un difunto - por ejemplo- es impura y no se pueden preparar en ella alimentos. ${ }^{87}$ No se puede comer alimento considerado impuro: "no comerás... lo considerarás impuro" (Lv 11), pero -por este mismo motivo- los extranjeros / paganos son personas que son impuras, con las que -por lo tanto- no se puede comer. ${ }^{88}$ Josefo nos señala que los esenios se purificaban con un baño después de tocar un extranjero:

Si un adulto es tocado por un joven, deben lavarse a sí mismos como si se hubiesen mezclado con la compañía de un extranjero (BJ 2,150).

En el libro de los Jubileos, se lee:

${ }^{83}$ Sobre este punto ver nuestro análisis del tema de la idolatría en 1 Corintios en un trabajo de próxima aparición en homenaje a L. H. Rivas.

${ }^{84}$ Con probable acierto, J. GNILKA, Pedro y Roma. La figura de Pedro en los dos primeros siglos de la Iglesia, Herder - Barcelona - 2003, 87, supone que la comida común incluye la comida eucarística.

85 S.A. Cummings, Paul and the Crucified Christ in Anthioc. Maccabean Martyrdom and Galatians 1 and 2. University Press - Cambridge - 2001, 164-180, 180.

${ }^{86}$ R. AguiRre, La mesa compartida. Estudios del NT desde las ciencias sociales, Presencia teológica 77, Sal Terrae - Bilbao - 1994, 35-49.126. Del mismo modo lo plantea M. SLEE, The Church in Anthioc in the First Century C.E. Communion and Conflict. Continuum International/T\&T Clark - London - 2004, 17-23, sobre la comunión de mesa. En p. 19 cita AZ 4,6: un judío que come en casa de un gentil es culpable de idolatría incluso si come su propia comida y bebe su propio vino e incluso si es servido por sus propios sirvientes. En pp. 42-43 pone el acento en que la mesa es (también) eucarística. 99.

87 R. DE VAUX, Instituciones del Antiguo Testamento, Herder, Barcelona, 1976,

88 Es interesante notar que los ángeles "no comen" sino que "parece" que lo hacen, Tob 12,19; cf. Evangelio del Pseudo Mateo 1,3. 
Hijo mío, Jacob, recuerda mis palabras y guarda los mandamientos de tu padre, Abrahán. Apártate de los gentiles, no comas con ellos, no hagas como ellos, ni les sirvas de compañero, pues sus acciones son impuras, y todos sus caminos inmundicia, abominación y horror..." (Jub 12,16)

En JosAs 7,1, José come aparte en Egipto; en 3 Mac 3,4 los judíos en Egipto se separaban en las comidas. Es muy importante -ademásnotar el evidente paralelo entre alimentos impuros y personas impuras que se ve en el relato de Cornelio, Hch 10,14.28:

Ustedes saben que le está prohibido a un judío juntarse con un extranjero o entrar en su casa; pero a mí Dios me ha mostrado que no hay que llamar profano o impuro a ningún hombre.

"Comer con" (sunesthíein) es el signo visible de acoger al "otro/a" como hermano/a. Mußner termina su comentario a Gálatas con estas palabras:

La iglesia del futuro se vuelve en esto conforme a la voluntad de Dios porque si no quiere traicionar a su Señor debe hacerlo visible en la vida. A partir de la carta a los Gálatas podemos decir que la naturaleza del cristianismo es sunesthiein. $^{89}$

La división de mesas abandona la unidad; se abandonó el Evangelio de la "justificación por la fe" para recaer en la ley. ${ }^{90}$ Análogamente a la colecta para los pobres de Jerusalén, la mesa común es un signo visible de la fraternidad. Si sólo se come con "hermanos", 91 negarse a compartir la mesa con alguien es no reconocerlo como tal. ${ }^{92}$ Esto es lo que provoca a Pablo a intervenir en Antioquía.

${ }^{89}$ MUBNER, Galaterbrief, 423.

90 Insistimos. no solamente la "ley" de alimentos, sino todo lo que implica la "ley" como una "vuelta atrás" al período anterior a estar "en Cristo". Es un "giro histórico de la historia que cierra la era de la ley y abre la era de la fe (Gal 3,23)", G. Barbaglio, La teología de San Pablo, Secretariado Trinitario - Salamanca - 2005, 252. D.J. VERSEPUT, "Paul's Gentile Mission and the Jewish Christian Community. A Study of the Narrative in Galatians 1 and 2", NTS 39 (1993) 58, lo dice de este modo: "Pablo no se está defendiendo de ataques personales en Gal 1 y 2, sino que está avanzando un argumento histórico para la independencia de las iglesias gentiles respecto de los confines de las normas de la Torá".

91 No hace falta señalar aquí la importancia de la categoría "hermano" y su relación con los miembros del pueblo de Dios, cf. H. RINGGREN, "אח", TDOT, I, 188-193,

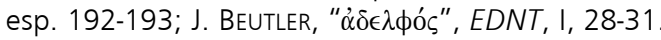

92 En DE LA SeRnA, "Mujer", hemos propuesto que la categoría "hermanos/as" es el término que permite "quebrar" la distancia entre judíos y paganos, esclavos y libres, machos y hembras. Sobre la colecta, como "compartir con el hermano" (y la posibilidad de que no fuera aceptada, precisamente porque algunos -los "incrédulos"- se 
Siendo que Pablo se dirige a Kefas "delante de todos", ¿esto necesariamente supone rompimiento? La posición relevante de Pedro en su accionar mueve "hasta a Bernabé". ¿Esto es indicio de un diferente concepto sobre la misión a los paganos entre Pablo y Bernabé (que Lucas suavizaría en Hch 15,36-40)? Lo cierto es que Pablo se siente autorizado para reprenderlo. La situación parece haber sido de tensión. No sabemos cómo fue todo, pero ciertos elementos de la vida de Pablo nos invitan a suponerlo. Así lo plantea J.P. Meier:

Rápidamente, Pablo asume una misión en Asia Menor y Europa sin Bernabé. Vuelve a Antioquía sólo para una breve visita (Hch 18,22). Nunca vuelve a mencionar a Antioquía de Siria en sus cartas [...] en Gálatas 2 silencia quién ganó el debate. Por estos hechos podemos inferir razonablemente que Pablo perdió. $^{93}$

Lo principal a tener en cuenta es que Pablo no narra este acontecimiento "contra" Pedro, sino a causa de sus adversarios en Galacia. Podemos decir que "ambos apóstoles tienen mucho más en común de lo que algunos críticos modernos están dispuestos a admitir". 94 Pablo no cuestiona la autoridad de Pedro sino, precisamente, que teniendo tal autoridad actúe indebidamente poniendo en cuestión la "libertad del evangelio". ${ }^{95}$ Se puede contrastar la actitud de Pablo cuando ve que los "falsos hermanos" pretenden "esclavizar" y "espiar la libertad", en cuyo caso Pablo los deja a un lado y se encuentra a solas con los "notables". En el incidente de Antioquía, en cambio, Pablo tiene claro el rol ministerial de Pedro y plantea el debate. Es obvio que Pablo,

niegan a reconocer a los paganos como hermanos), cf. 382-386; cf. tb. P.C. BötTGeR, "Paulus und Petrus in Antiochien. Zum Verständnis von Galater 2,11-21", NTS 37 (1991) 77-100.

93 R.E. Brown - J.P. MeIer, Antioch \& Rome. New Testament Cradles of Catholic Christianity, Paulist - New York/Ramsey - 1982, 39 (también otros sostienen este punto de vista); esta mirada es cuestionada por LOHSE, "Peter's Apostleship", 432.

94 LOHSE, "Peter's Apostleship", 435.

95 En este sentido, no nos parece feliz la idea de que Pablo en 1,18 es inferior a Kefas (por "pedir información"), en 2,7-8 es igual a Kefas (a quienes se les confía por igual el evangelio) y en 2,11-12 es superior a Kefas y se puede enfrentar a él cara a cara (cf. Brown et al., Pedro, 37). Pablo se sabe Apóstol, elegido por el Señor que se le apareció, y puede buscar a Kefas para conocer mejor la tradición; pero no se siente menor, ni tampoco se siente mayor a él por reprocharle algo. Sí se siente fiel al evangelio, intachable; y como tal, puede ver un comportamiento que no es coherente. Pero no parece que se vea como superior en ningún modo. 
narrando esto a los gálatas, pretende poner su apostolado en comparación con "la indudable autoridad de Pedro". 96

Al destacar el protagonismo de Pedro y su enfrentamiento con él, Pablo está reconociendo implícitamente la autoridad de Cefas, tanto en el momento histórico del conflicto como en la impresión que la narración del mismo puede producir en los gálatas corroborando y afirmando la conducta e interpretación paulina del evangelio. ${ }^{97}$

No parece sensato que se lea el conflicto de Pedro y Pablo en Antioquía como un "anticipo" del conflicto luterano-católico del s. XVI, como bien lo plantea Gnilka, citando luego a Schenk: "dime cómo sorteas Gal 2,11ss y te diré qué clase de cristiano eres". ${ }^{98}$

Un aspecto conclusivo es saber dónde termina la unidad referida a Pedro. Algunos autores piensan que ésta concluye recién en v. 21, ya que con sus actitudes, Pedro "anula la gracia de Dios", "corre el riesgo de 'trasgredir' el plan de Dios” y así, "15-17 refiere principalmente al pasado, la conversión de Pedro y Pablo, mientras que 18-21 apunta principalmente a la vida típicamente cristiana posterior a la conversión"; ellos pueden "estar tentados de volver a un viejo estilo de vida anterior a la conversión, caracterizado por la obediencia a la ley. Obrar en consecuencia puede significar nada menos que anular la gracia de Dios". ${ }^{99}$ Agourides por su parte, piensa -probablemente con razón- que 11-14 presenta el incidente de Antioquía, mientras que 15-21 es el comentario teológico del mismo Pablo, destinado a los gálatas. ${ }^{100} \mathrm{De}$ todos modos, es evidente que 2,15-21 aunque no es ajena al tema que Pablo plantea; está teologizando no ya sobre Pedro/Kefas sino sobre el Evangelio que Pablo predica, y escapa a nuestro tema.

96 E. LOHSE, "Peter's Apostleship", 434.

97 F. Pastor Ramos, "Pedro en el Corpus paulino", Pedro en la Iglesia primitiva (R. Aguirre Monasterio et al.), Instit. San Jerónimo 23, Verbo Divino - Navarra - 1991, 114; y en nota agrega: "B. Holmberg o.c. 34 [se refiere a Paul and Power. The Structure of Authority in the Primitive Church as Reflected in the Pauline Epistles, Filadelfia - 1980]: 'Otra cosa que demuestra la crisis de Antioquía es la fuerza de autoridad de Cephas.' Sin embargo puede ser demasiado decir que esta autoridad era sobre toda la Iglesia como hace J. M. González Ruiz, "Pedro en Antioquía jefe de toda la Iglesia según Gal 2,11-14", Studiorum Paulinorum Congressus Internationalis Catholicus, Romae - 1963, II,11-16.

98 GNILKA, Pedro y Roma, 86-87.

99 I. LAMBRECHT, "Paul's Argumentation in Galatians and Its Relevance Today", Truth of the Gospel, 233-248, 242-243.

100 Agourides, "Peter and Paul", 61. 


\subsection{Aparente referencia a Pedro}

Un tema que a veces se plantea en los estudios sobre "Pedro" en Pablo es la referencia a textos que aparentemente aludirían a Simón, pero no lo hacen explícitamente. Simplemente digamos que todo esto se mueve -y lo hemos señalado en más de una ocasión- en el terreno de lo hipotético. Los materiales que hemos analizado nos permiten extraer elementos conclusivos un poco más seguros.

A modo de una primera conclusión, nos parece útil seguir en esto a F. Pastor Ramos:

- Pedro tiene una posición de tal relevancia que muchos cristianos se sienten influidos con su ejemplo (que Bernabé lo imite, indica su influencia);

- Pablo se siente facultado para reprender públicamente a Pedro cuando a su juicio, la conducta de éste no es acertada;

- Lo que significa que esa supremacía de Pedro no está tan fuera del plano de la igualdad con otros apóstoles. No es autónoma o suprema sin más;

- La función de Pedro, tal como él parece entenderla, tiene visos de ser vínculo de unión y comunión entre los cristianos. Quizás más en el plano práctico que teórico. ${ }^{101}$

\section{Conclusión}

Un elemento principal a tener en cuenta es que las cartas ya suponen un reconocimiento de la autoridad de Pedro fuera del ambiente siro-palestinense. Esto no sólo remite a su probable actividad misionera fuera de este espacio, sino -sobre todo- a que el nombre "Kefas" ya era un nombre "cargado de contenido" en el cristianismo primitivo. ${ }^{102}$ Es evidente que, cuando Pablo alude a Kefas, está haciendo referencia a

101 PAstor Ramos, "Pedro", 116.

102 Como lo hemos dicho, no nos referimos al sentido de "Kefas" = piedra de la Iglesia, sino a que es una persona bien conocida en las Iglesias. 
alguien que goza de gran autoridad en sus comunidades; y una autoridad que le viene dada no sólo por ser el primer beneficiario de una aparición del resucitado, no sólo por ser testigo de las tradiciones de Jesús, y "apóstol antes que Pablo" (cf. Rom 16,7), no sólo por ser misionero itinerante o reputada columna de la Iglesia de Jerusalén. Kefas tiene un "plus" además de todo esto. Y el hecho de que sea la "autoridad" a la que Pablo constantemente refiere, aunque sea para "enfrentarla", ciertamente lo manifiesta.

La figura simbólica de Pedro ya era importante como expresión de comunión; es evidente que en la segunda mitad del s. I hay más petrinismo que paulinismo. Así crece en la tradición de 1 Pe, de Jn y de 2 Pe. Ignacio de Antioquía los menciona juntos, a pesar de que en Antioquía parece que Pedro ya era importante y Pablo no tanto, seguramente por la relación de ambos con Roma (lo mismo vale para la referencia a Pablo en 2 Pe 3,15).

También podemos afirmar que es posible ver en diferentes textos del Nuevo Testamento actitudes críticas a la tradición paulina (cf. Sant; 2 $\mathrm{Pe}$ ), y una tradición paulina que busca defender al Apóstol. Sin tomar posición, valga como ejemplo notar que recientemente se ha insistido en el carácter "antipaulino" del Evangelio de Mateo, compuesto con toda probabilidad en Antioquía. ${ }^{103}$

Pero, curiosamente, por otro lado, Pedro está ausente en las deuteropaulinas y pastorales, lo que es especialmente extraño dada la importancia que en ellas se da a la estructuración y a la teología de la Iglesia, por lo que parece evidente que la figura de Pedro no monopolizó el ministerio, la tradición, la organización eclesial, el depósito de la fe y la misión... Estos autores se apoyan en la autoridad de Pablo para sostener estos planteos y no ven necesario recurrir a la figura de Pedro para validarlos (lo que sí hace la $1 \mathrm{Pe}$, también ligada a la tradición paulina). Pedro es el Primer apóstol, pero lo es en el plano de la comunión, y aun de igualdad con otros apóstoles. Entre ellos, Pablo. ${ }^{104}$

Epifanio de Salamina y Eusebio de Cesarea nombran a Pedro y a Pablo como obispos de Roma, cosa que se reforzó con la fijación de la

103 D.C. SIM, "Matthew 7,21-23: Further Evidence of its Anti-Pauline Perspective", NTS 53 (2007) 325-343, donde -continuando anteriores trabajos, citados en n. 1propone que los falsos profetas carismáticos están claramente asociados a Pablo y/o a sus iglesias.

104 Cf. PAstor Ramos, "Pedro", 116. 
fecha litúrgica relacionada con la fecha de la fundación de Roma (en las $3^{\text {as }}$ calendas se conmemoraba la fundación de las Aedes Quirini, los fundadores de Roma y se los reconoce como los fundadores de la comunidad). ${ }^{105}$

No cabe duda de que para Pablo, lo que cuenta es la gracia, la iniciativa de Dios. Ya lo había señalado -lo vimos- al narrar las apariciones del resucitado (1 Cor 15,3-8), pero también lo presenta de un modo claramente paralelo en Gal 2,7-8, lo que resalta claramente la semejanza de los ministerios:

a a mí me ha sido confiado el evangelio de los incircuncisos

b como a Pedro el de los circuncisos

b' pues Aquel que ha obrado en Pedro para el apostolado de los circuncisos

a' ha obrado también en mí para los gentiles. ${ }^{106}$

Se trata de la iniciativa de Dios que da sentido al ministerio y al evangelio, de Pedro y de Pablo, iniciativa que no permite "jactarse" sino reconocer que para él sólo cabe "predicar el Evangelio entregándolo gratuitamente, renunciando al derecho que me confiere el Evangelio" (1 Cor 9,18). Pedro o los que lo siguen, podrían mostrar muchos antecedentes que destaquen su importancia en las comunidades primitivas; Pablo y los suyos también podrían hacerlo. Para Pablo todo esto es necedad, sólo cuenta la obra de Dios. Y quien se jacte, sólo debe jactarse en el Señor (1 Cor 1,31; 2 Cor 10,17).

Sin duda, Pedro es visto como autoridad. También lo es Pablo. Pero una autoridad que no se eleva sobre los demás, sino como primus inter pares, como verdadero hermano. Nada es más importante, desde el bautismo, que saberse hijos de Dios, y hermanos/as los/as unos/as de los/as otros/as. La fraternidad es probablemente uno de los términos fundamentales de la vida cristiana primitiva. ${ }^{107}$ Es precisamente el atentado contra la fraternidad lo que preocupa a Pablo en Antioquía, cuando no se reconoce a los no judíos como hermanos y se los excluye de

105 D. Álvarez Cineira, "Muerte", 474.

106 Tomamos este esquema de PANIMOLLE, "Autorité", 273.

107 Cf. R. AASGAARD, "'Role Ethics' in Paul: The Significance of the Sibling Role for Paul's Ethical Thinking", NTS 48 (2002) 513-530, que en realidad es parte de su tesis doctoral -dirigida por H. Moxnes-, luego publicada como "My Beloved Brothers and Sisters!". Christian Siblings in Paul, T\&T Clark - London - 2004. 
la mesa o se los fuerza a judaizar. En la vida y ministerio de Pablo, no todo era "color de rosa". Muchos no sacaron todas las consecuencias fundamentales que Pablo encuentra en el Bautismo y determinados comportamientos los retrotraen al viejo eón ya pasado:

El bautismo es el inicio de la vida nueva del creyente; lo pone en relación con Cristo, en una relación tal que lo hace vivir en el nuevo tiempo (= eón), que lo hace entrar en un modo nuevo de relación con los hermanos (miembros del mismo cuerpo). La unidad que se establece entre los bautizados es más fuerte que toda relación que se pueda establecer entre los seres humanos... No puede dejarse de lado el sentido escatológico del bautismo: supone unión con la muerte y resurrección de Cristo, y estar "en Cristo". ${ }^{108}$

Es por el reconocimiento mutuo de la fraternidad/sororidad originada en el bautismo, por lo que Pablo se enfrenta; tal es la novedad del evangelio, el sentido de estar "en Cristo", en el nuevo eón. A modo de conclusión, notemos la importancia del uso del término "hermano" y su posterior "reducción" en la historia de la Iglesia con una interesante cita:

En los primeros siglos de la historia cristiana, los cristianos de todos los órdenes se llamaban mutuamente hermanos y hermanas, de acuerdo con las palabras del Señor: "No os hagáis llamar rabí, porque uno es vuestro maestro, y todos vosotros sois hermanos. No llaméis tampoco a nadie en la tierra padre, pues uno es vuestro Padre, el celestial" (Mt 23,8s.). Según esto, las comunidades de las Iglesias locales se llamaban adelfótês, comunidad de hermanos. En el siglo II encontramos una importante reducción en el empleo de estos términos, cuyo exponente más claro vienen a ser quizá las cartas de san Cipriano. Ciertamente sigue dirigiéndose a su grey con el saludo "amados hermanos", pero en el diálogo individual sólo usa la palabra "hermano" cuando se dirige a obispos o clérigos. Los presbíteros y diáconos de Roma, por el contrario, lo saludan en su carta como "beatissime et gloriosissime papa"; la dirección de la misma, consecuentemente, dice: "Cypriano papae".

Cuando Cipriano, obispo de Cartago, y Cornelio, obispo de Roma se escriben mutuamente, encontramos la palabra "hermano" en el encabezamiento; pero se trata ya un poco de un título de personas de igual rango a las que sus subordinados debían llamar "papa". Estamos ante una primera reducción: el término "hermano" ya no engloba a toda la Iglesia, sino a un estrecho círculo dentro de ella, en el que se polariza también entonces el título de "fraternitas" (adelfótês). Pronto se opera una segunda reducción: la palabra "hermano", en la que todavía alienta la sencillez del Evangelio y su superación de todo aparato jerarquizante, con el correr de los tiempos es desplazada cada vez más por el título formal de "collega" tomado del Derecho romano; simultáneamente es eliminado el término "fraternitas" y sustituido por el de "collegium", que en los 
siglos IV y $\mathrm{V}$ aparece como la manera ordinaria de designar a la comunidad de los obispos; los otros términos que en esta misma época encontramos, como "ordo" y "corpus", están tomados también del Derecho romano y ponen de manifiesto la misma evolución que acabamos de señalar. ${ }^{109}$

EDUARDO DE LA SERNA

QUILMES

eduardo.de.la.serna@gmail.com

109 J. RATZINGer, "Implicaciones pastorales de la doctrina de la colegialidad de los obispos", Concilium 1 (1965) 44-46; cf. ID., El nuevo Pueblo de Dios, Herder - Barcelona - 1972, 285-288. 